\title{
Analysis of feedbacks between nucleation rate, survival probability and cloud condensation nuclei formation
}

\author{
D. M. Westervelt ${ }^{1, *}$, J. R. Pierce ${ }^{2}$, and P. J. Adams ${ }^{1}$ \\ ${ }^{1}$ Center for Atmospheric Particle Studies (CAPS), Carnegie Mellon University, Pittsburgh, PA, USA \\ ${ }^{2}$ Department Atmospheric Science, Colorado State University, Fort Collins, CO, USA \\ "now at: Program in Science, Technology, and Environmental Policy, Woodrow Wilson School of Public and International \\ Affairs, Princeton University, Princeton, NJ, USA
}

Correspondence to: P. J. Adams (petera@andrew.cmu.edu)

Received: 26 November 2013 - Published in Atmos. Chem. Phys. Discuss.: 10 December 2013

Revised: 21 April 2014 - Accepted: 22 April 2014 - Published: 5 June 2014

\begin{abstract}
Aerosol nucleation is an important source of particle number in the atmosphere. However, in order to become cloud condensation nuclei $(\mathrm{CCN})$, freshly nucleated particles must undergo significant condensational growth while avoiding coagulational scavenging. In an effort to quantify the contribution of nucleation to $\mathrm{CCN}$, this work uses the GEOS-Chem-TOMAS global aerosol model to calculate changes in $\mathrm{CCN}$ concentrations against a broad range of nucleation rates and mechanisms. We then quantify the factors that control $\mathrm{CCN}$ formation from nucleation, including daily nucleation rates, growth rates, coagulation sinks, condensation sinks, survival probabilities, and $\mathrm{CCN}$ formation rates, in order to examine feedbacks that may limit growth of nucleated particles to $\mathrm{CCN}$. Nucleation rate parameterizations tested in GEOS-Chem-TOMAS include ternary nucleation (with multiple tuning factors), activation nucleation (with two pre-factors), binary nucleation, and ion-mediated nucleation. We find that nucleation makes a significant contribution to boundary layer $\mathrm{CCN}(0.2 \%)$, but this contribution is only modestly sensitive to the choice of nucleation scheme, ranging from 49 to $78 \%$ increase in concentrations over a control simulation with no nucleation. Moreover, a two order-of-magnitude increase in the globally averaged nucleation rate (via changes to tuning factors) results in small changes (less than $10 \%$ ) to global $\mathrm{CCN}(0.2 \%)$ concentrations. To explain this, we present a simple theory showing that survival probability has an exponentially decreasing dependence on the square of the condensation sink. This functional form stems from a negative correlation between condensation sink and growth rate and a positive correlation be-
\end{abstract}

tween condensation sink and coagulational scavenging. Conceptually, with a fixed condensable vapor budget (sulfuric acid and organics), any increase in CCN concentrations due to higher nucleation rates necessarily entails an increased aerosol surface area in the accumulation mode, resulting in a higher condensation sink, which lowers vapor concentrations and growth rates. As a result, slowly growing nuclei are exposed to a higher frequency of coagulational scavenging for a longer period of time, thus reducing their survival probabilities and closing a negative feedback loop that dampens the impact of nucleation on CCN. We confirm quantitatively that the decreases in survival probability predicted by GEOS-Chem-TOMAS due to higher nucleation rates are in accordance with this simple theory of survival probability.

\section{Introduction}

Aerosols affect climate directly by scattering incoming solar radiation and indirectly by modifying cloud properties. The largest uncertainty in climate forcing is the aerosol indirect effect, which consists of the cloud brightness (albedo) effect and the cloud lifetime effect and is thought to have an overall cooling influence on global temperature (Twomey, 1974; Albrecht, 1989). If water vapor amount and cloud dynamics are held constant, brighter clouds with longer lifetimes are formed with enhanced aerosol number concentrations. The subset of particles that serve as sites for cloud droplet formation are known as cloud condensation nuclei $(\mathrm{CCN})$. The ability of a particle to function as a $\mathrm{CCN}$ mainly 
depends on three factors: the maximum supersaturation of relative humidity reached in the cloud, the particle diameter, and the particle composition. In order for particles to affect clouds, they are either introduced into the atmosphere by direct emission or by formation of new particles (aerosol nucleation). Nucleated particles and ultrafine particles from primary emissions must undergo significant growth to achieve the sizes required to function as CCN (Kerminen, 2005; Pierce and Adams, 2007; Kuang et al., 2009). The representation of nucleation in models is uncertain with ordersof-magnitude differences in nucleation rates between commonly used schemes, leading to uncertainty in estimates of the nucleation contribution to CCN (Makkonen et al., 2009; Merikanto et al., 2009; Pierce and Adams, 2009b; Wang and Penner, 2009; Yu and Luo, 2009; Spracklen et al., 2010; Reddington et al., 2011). The role of sulfuric acid vapor as an essential nucleating species has been reported by many studies (Doyle, 1961; Kulmala and Laaksonen, 1990; Weber et al., 1995, 1997; Noppel et al., 2002; Berndt et al., 2005; Sihto et al., 2006; Kuang et al., 2008; Sipilä et al., 2010; Vuollekoski et al., 2010; Pierce et al., 2012; Kulmala et al., 2013). Other vapors that may assist in the initial stages of nucleation include low-volatility organic vapors (Zhang et al., 2004; Metzger et al., 2010; Paasonen et al., 2010), amines (Kurtén et al., 2008; Bzdek et al., 2010; Kirkby et al., 2011; Chen et al., 2012; Almeida et al., 2013), and ammonia (Ball et al., 1999; Erupe et al., 2010; Kirkby et al., 2011). Chen et al. (2012) recently proposed an acid-base nucleation mechanism involving sulfuric acid and amines and achieved nucleation rate closure to within a factor of 10 , which is significantly better than classical theories which differ by as much as a factor of $10^{10}$. Additionally, a laboratory study by Almeida et al. (2013) recently showed that amines may help explain observed nucleation rates in the lower atmosphere.

Many parameterizations have been developed for calculating nucleation rates in global models; we highlight a few that are commonly used below. The binary nucleation parameterization of Vehkamäki et al. (2002) is often used to represent particle nucleation in the free troposphere. In this scheme, supersaturated solutions of water vapor and sulfuric acid form thermodynamically stable clusters. The Napari et al. (2002) parameterization adds ammonia $\left(\mathrm{NH}_{3}\right)$ as a third nucleating species. Because the original formulation of $\mathrm{Na}-$ pari et al. (2002) showed high biases in predictions of nucleation rates and aerosol number concentrations (Jung et al., 2006; Merikanto et al., 2007), a scaled version with a globally constant nucleation rate tuning pre-factor of $10^{-5}$ can be used as in Westervelt et al. (2013). This modified ternary parameterization has been incorporated into a both a regional and global aerosol model and shows reasonable agreement with observations (Jung et al., 2010; Westervelt et al., 2013). The activation nucleation mechanism (Kulmala et al., 2006) is an empirical formulation which is often applied in the planetary boundary layer (PBL) in conjunction with the binary scheme of Vehkamäki et al. (2002) in the free tropo- sphere. Although the nucleation rate is simply proportional to sulfuric acid concentration, activation nucleation has been shown to agree well with ambient nucleation observations at five locations (Westervelt et al., 2013). Ion-mediated nucleation, (Yu, 2010) in which atmospheric ionization enhances the nucleating ability of precursor vapors is also considered in the present work. Ion-mediated nucleation rates and number concentrations have compared favorably to observations in a global model (Yu and Turco, 2011), although other studies have found that ions do not likely play a large role in boundary layer nucleation (Laakso et al., 2007; Manninen et al., 2009; Gagné et al., 2010; Kirkby et al., 2011; Almeida et al., 2013).

Understanding the growth and loss processes of fresh nuclei is a critical step in determining the contribution of nucleation events to aerosol number and $\mathrm{CCN}$ concentrations. Whether or not a nucleated particle can act as a CCN depends on its survival probability (SP): the likelihood that the particle will grow to large enough sizes (typically at least 50-100 nm) without being subject to coagulation scavenging (Kerminen, 2005; Pierce and Adams, 2007; Kuang et al., 2009). The concept of survival probability is defined rigorously in Westervelt et al. (2013) and in Sect. 2.3 of this paper. Although both primary and nucleated particles undergo the same microphysical processes (condensation, coagulation), their survival probabilities may be vastly different due to their very different initial particles sizes. Initial sizes of nucleating clusters are typically $\sim 1 \mathrm{~nm}$ in size, which is much smaller than any primary emission size ranges (Mäkelä et al., 1997; Vehkamäki et al. 2002; Kulmala et al., 2004, 2013). Because of this size disadvantage, particles formed via nucleation have further to grow through a larger range of sizes and are exposed to coagulation scavenging for longer periods of time than primary emissions. Additionally, these smaller particles are highly diffusive and more likely to collide with pre-existing particles. Coagulational frequency is therefore higher between fresh nuclei and larger pre-existing particles, adding to the disadvantage that nucleated particles have to grow to CCN sizes. Kuang et al. (2009) inferred survival probabilities from size distribution measurements and found that at least $80 \%$ of the nucleated particles measured at Atlanta, GA and Boulder, $\mathrm{CO}$ were lost by coagulation before the nucleation mode reached $\mathrm{CCN}$ sizes in the cases that they studied ( $20 \%$ survival probability), even during days with high growth rates.

Most attempts to quantify the contribution of nucleation events to global CCN concentrations have come in the form of sensitivity studies in which nucleation is zeroed out as a control simulation and then is compared to simulations with nucleation active. Modeling studies have reported CCN sensitivities to nucleation ranging from roughly 5-60\% (Makkonen et al., 2009, 2012; Merikanto et al., 2009; Pierce and Adams, 2009b; Reddington et al., 2011; Spracklen et al., 2008, 2010; Wang and Penner, 2009; Yu and Luo, 2009). Each of these studies used different models and 
often significantly different inputs, assumptions, and metrics for assessing CCN sensitivity, making model intercomparison difficult. The details of these studies are compared in depth in Westervelt et al. (2013) and also in Table 1. Recently, Lee et al. (2013) compiled 28 model parameters covering several important aerosol processes and ran Monte Carlo simulations to determine the magnitude of uncertainty in $\mathrm{CCN}$ concentrations caused by each parameter. They find that while $45 \%$ of $\mathrm{CCN}$ are attributed to nucleation, the $\mathrm{CCN}$ are generally insensitive to the details of the nucleation rates across a wide, but sensible, range of boundary layer and freetropospheric nucleation assumptions. On the other hand, the most important factors contributing to uncertainties in $\mathrm{CCN}$ include the emissions size distribution of primary particles, the amount of carbonaceous emissions, sub-grid sulfate formation, and aerosol deposition.

The relative insensitivity of $\mathrm{CCN}$ concentrations to very large increases in the nucleation rate can be explained in four steps: (1) for fixed condensable vapor production rates, an increase in aerosol number due to nucleation and subsequent growth causes an increase in surface area in the accumulation mode and a higher condensation sink; (2) the higher condensation sink depletes vapors needed for particle growth; thus, the concentrations of condensable vapors are reduced and growth rates are slowed; (3) the higher condensation sink also correlates with higher coagulation scavenging frequencies; thus, a larger fraction of the growing particles are scavenged (even if growth rates were held constant, which they are not); (4) this combination of the slower growth rates and the faster coagulation scavenging lower particle survival probabilities and $\mathrm{CCN}$ formation rates. Although $\mathrm{CCN}$ concentrations will typically not decrease as a result of increased nucleation, the increase in $\mathrm{CCN}$ will be dampened such that their fractional increase in $\mathrm{CCN}$ will be much smaller than the fractional increase in the nucleation rate.

The increase in surface area due to nucleation (step 1 above) requires elaboration since conventional wisdom holds that the surface area of the nucleation mode is too small to contribute significantly to surface area. There are two main reasons the surface area (and thus condensation sink) will increase from enhanced nucleation rates. First, the atmosphere has a limited budget of condensable vapors, sulfuric acid and secondary organics, that dominate the mass concentration of $\mathrm{CCN}$ mode particles. Given the fixed amount of aerosol mass produced, any increase in $\mathrm{CCN}$ number concentrations (e.g., due to nucleation) implies a shift in the $\mathrm{CCN}$ mode to smaller sizes and, therefore, an increase in aerosol surface area and condensation sink. This effect is analogous to the aerosol indirect effect in which a fixed water vapor budget implies an increase in cloud surface area if number concentrations increase. Second, the direct contribution of nucleated particles to surface area and condensation sink is non-negligible. For events with high nucleation and growth rates, enough nucleation mode particles will form to compensate for their small surface area contribution (we will show an example of this).
This can result in a small but non-negligible enhancement in the surface area over the course of a nucleation burst.

In this work, we quantify the global sensitivity of $\mathrm{CCN}$ to uncertainties in nucleation rates across a wide range of nucleation rates in a global aerosol microphysics model (GEOSChem-TOMAS) in an attempt to help unify the previous studies of this sensitivity. We also compare CCN sensitivities for simulations with biogenic secondary organic aerosol (SOA) only (19 $\mathrm{Tg} \mathrm{yr}^{-1}$, default treatment in GEOS-ChemTOMAS) and simulations with an extra $100 \mathrm{Tg} \mathrm{yr}^{-1}$ of anthropogenic SOA (Spracklen et al., 2011; D'Andrea et al., 2013). Here, CCN sensitivity refers to the percent increase in CCN concentrations between two simulations with differing nucleation rates and mechanisms (generally the comparison is between a simulation with no nucleation to a simulation with a certain nucleation scheme turned on). We also investigate the microphysics of $\mathrm{CCN}$ formation in detail with one year of modeled size distribution output to determine quantitatively the feedback factors that are controlling our sensitivity results. We specifically test the hypothesis that higher nucleation rates will lead to a lower survival probability and will dampen $\mathrm{CCN}$ concentrations using global modeling results and the nucleated particle analysis code presented in Westervelt et al. (2013). We propose a simple theory for the hypothesized $\mathrm{CCN}$ dampening in which particle survival probability is inversely related to condensation sink and show that model results are generally consistent with this simple theory.

\section{Models and analysis}

\subsection{GEOS-Chem}

The Goddard Earth Observing System global chemical transport model (GEOS-Chem) version 8.2.2 is used for this study (Bey et al., 2001; http://geos-chem.org). The version of GEOS meteorological fields used was GEOS-3 for all simulations. In all simulations, $4^{\circ}$ latitude by $5^{\circ}$ longitude resolution is used with 30 vertical sigma-coordinate layers extending from the surface to $0.01 \mathrm{hPa}$. We describe a few key model setup features here but refer the reader to Trivitayanurak et al. (2008) and Westervelt et al. (2013) for full details. Anthropogenic emissions are treated with the Emissions Database for Global Atmospheric Research (EDGAR) inventory and regional inventories (Olivier et al., 1996). These regional inventories include Big Bend Regional Aerosol and Visibility Observational Study (BRAVO) emissions inventory for Mexico and the southwestern US, Criteria Air Contaminants (CAC) for anthropogenic emissions over Canada (http://www.ec.gc.ca/inrp-npri/), the Cooperative Programme for Monitoring and Evaluation of the Long-range Transmission of Air Pollutants in Europe (EMEP), EPA National Emissions Inventory (NEI) for the United States (http://www.epa.gov/airdata/), and the Streets 
Table 1. Summary of previous nucleation-CCN formation studies. Values are $\mathrm{CCN}(0.2 \%)$ except for Yu and Luo (2009) which used $\mathrm{CCN}(0.4) \%$.

\begin{tabular}{llllr}
\hline Study & Model & Bounds & Pri. Sulf. & $\%$ change \\
\hline Spracklen et al. (2008) & GLOMAP & ACT vs. NONUC & $2.5 \%$ of $\mathrm{SO}_{2}$ emis. & 20 \\
Merikanto et al. (2009) & GLOMAP & BHN + ACT vs. BHN & $2.5 \%$ of $\mathrm{SO}_{2}$ & 45 \\
Makkonen et al. (2009) & ECHAM5-HAM & BHN + ACT vs. BHN & $2.5 \% \mathrm{SO}_{2}$ & 50 \\
Yu and Luo (2009) & GEOS-Chem-APM & ION vs. NONUC & None & 60 \\
Wang and Penner (2009) & IMPACT/CCSM3 & BHN + ACT vs. BHN & $2 \%$ of $\mathrm{SO}_{2}$ & 5 \\
Pierce and Adams (2009b) & GISS-TOMAS & TER vs. BHN & $1 \%$ of $\mathrm{SO}_{2}$ & 12 \\
Makkonen et al. (2012) & ECHAM5.5-HAM2 & ACT vs. BHN & $2.5 \%$ of $\mathrm{SO}_{2}$ & 19 \\
Lee et al. (2013) & GLOMAP & ACT + BHN vs. NONUC & $0-1 \%$ of $\mathrm{SO}_{2}$ & 45 \\
\hline
\end{tabular}

inventory for Asian emissions (Streets et al., 2003; Auvray and Bey, 2005). Biogenic emissions in the model follow the MEGAN database, and biomass burning emissions use the Global Fire Emissions Database version 2 (GFEDv2) (Guenther et al., 2006). $\mathrm{NO}_{\mathrm{x}}$ emissions from aircraft, lightning, and soil are considered in the global model. Shipping $\mathrm{SO}_{\mathrm{x}}$ emissions are considered within EDGAR and EMEP.

\subsection{TwO-Moment Aerosol Sectional (TOMAS) algorithm}

As in Westervelt et al. (2013), aerosol microphysical processes such as condensation, coagulation, and nucleation are calculated using the TwO Moment Aerosol Sectional algorithm (TOMAS) (Adams and Seinfeld, 2002). TOMAS was introduced as a regular component of the host model GEOSChem in version 8.2.2 and 8.3.1 and is available for download (www.geos-chem.org). Advantages of the TOMAS algorithm and GEOS-Chem implementation include the fact that all aerosol species have explicit, interactive microphysics and TOMAS conserves number and mass concentrations, allowing calculation of aerosol number budgets. Generally, we employ the work of Trivitayanurak et al. (2008) and Westervelt et al. (2013) with the organic aerosol additions of Pierce et al. (2007), the dust additions of Lee et al. (2009), and the nucleation implementations of Pierce and Adams (2009a). There are a number of nucleation theories added to the model, which are described in Sect. 2.2.1. TOMAS computes the effects of nucleation, coagulation, condensation/evaporation, cloud processing, size-resolved dry and wet deposition, and emissions on the number and mass size distribution of aerosols (Tzivion et al., 1987; Adams and Seinfeld, 2002). Aerosol chemical composition is represented by nine species: sulfate, sea salt, hydrophilic and hydrophobic organic carbon, externally and internally mixed elemental carbon, mineral dust, ammonium, and aerosol water. Each of the nine species is tracked across 40 logarithmically spaced size sections covering a diameter range of $1.1 \mathrm{~nm}$ to $10 \mu \mathrm{m}$, resulting in 360 TOMAS-specific model tracers. Primary sulfate aerosol emissions are $1 \%$ of anthropogenic $\mathrm{SO}_{2}$ emissions and use the size distributions de- scribed in Adams and Seinfeld (2003). Sea salt emissions are treated in the same manner as in Trivitayanurak et al. (2008) and are described in detail in Pierce and Adams (2006). Organic aerosols are unchanged from Westervelt et al. (2013), except for some changes to SOA condensation which are discussed in Sect. 2.2.3. Advection, chemistry, and deposition have remained largely unchanged from the work of Trivitayanurak et al. (2008), although periodic minor updates in both advection and chemistry (e.g., newer reaction rate constants and photolysis constants) have been implemented into successive versions of GEOS-Chem.

\subsubsection{Nucleation simulations}

We have implemented a number of nucleation mechanisms into the model. As in Westervelt et al. (2013), binary homogenous nucleation (Vehkamäki et al., 2002), ternary homogenous nucleation (Napari et al., 2002), and activation nucleation (Kulmala et al., 2006; Sihto et al., 2006) are included. The various simulations that we perform with the different nucleation theories are described in Table 2. Binary nucleation (BHN) alone is one simulation. For ternary nucleation, we employ three different simulations: one with a globally applied $10^{-5}$ tuning factor on the nucleation rate (TER5), another with a $10^{-3}$ tuning factor (TER3), and a third with no tuning factor (the original formulation, TER). Ternary nucleation defaults to binary nucleation when $\mathrm{NH}_{3}$ mixing ratios are below $0.1 \mathrm{pptv}$ since the ternary nucleation scheme predicts no nucleation below this $\mathrm{NH}_{3}$ mixing ratio. Activation is also broken up into multiple simulations: one with the $A$ pre-factor equal to $2 \times 10^{-6} \mathrm{~s}^{-1}$, and another with $A=1 \times 10^{-6} \mathrm{~s}^{-1}$. The factor-of-two change in the $A$ value is smaller than order-of-magnitude changes evaluated in previous studies (Spracklen et al., 2008, 2010). We use this smaller perturbation in nucleation rates to determine how much CCN will increase due to a relatively smaller enhancement in nucleation rates compared to our ternary simulations (TER, TER3, TER5). The activation nucleation schemes only act in the boundary layer, and binary nucleation is used in the free troposphere in these simulations. We employ the ion-mediated nucleation (IMN) of (Yu, 2010) as 
Table 2. List of simulations. All eight simulations were also run at higher SOA production rates, as described in the text.

\begin{tabular}{|c|c|c|}
\hline Name & Nucleation & Reference \\
\hline NONUC & None (control) & N/A \\
\hline BHN & Binary homogenous & Vehkamäki et al. (2002) \\
\hline ION & Ion-mediated (IMN) & Yu (2010) \\
\hline ACT1 & Activation $\left(\mathrm{A}=10^{-6}\right)$ & $\begin{array}{l}\text { Kulmala et al. (2006), } \\
\text { Sihto et al. (2006) }\end{array}$ \\
\hline ACT2 & Activation $\left(\mathrm{A}=2 \times 10^{-6}\right)$ & $\begin{array}{l}\text { Kulmala et al. (2006), } \\
\text { Sihto et al. (2006) }\end{array}$ \\
\hline TER5 & Ternary $\left(10^{-5}\right.$ tuning factor $)$ & $\begin{array}{l}\text { Napari et al. (2002), } \\
\text { Jung et al. (2006), } \\
\text { Westervelt et al. (2013) }\end{array}$ \\
\hline TER3 & Ternary $\left(10^{-3}\right.$ tuning factor $)$ & $\begin{array}{l}\text { Napari et al. (2002), } \\
\text { Jung et al. (2006), } \\
\text { Westervelt et al. (2013) }\end{array}$ \\
\hline TER & Ternary (no tuning factor) & Napari et al. (2002) \\
\hline
\end{tabular}

another simulation. Finally, we perform a control simulation (NONUC) where all nucleation is turned off in the global model, which gives eight simulations total. Simulations were run for a total of 13 months, with 1 month of spin-up, which is not used in the analysis.

As in Westervelt et al. (2013), gas-phase sulfuric acid concentrations are calculated using a pseudo-steady-state approach for each time step (Pierce and Adams, 2009a). Additionally, the lower boundary on the size distribution of $1.1 \mathrm{~nm}$ allows for explicit simulation of the dynamics of fresh nuclei (Lee et al., 2013).

\subsubsection{CCN calculations}

Cloud condensation nuclei formation in the GEOS-ChemTOMAS model is similar to the methods described in past model versions (Pierce et al., 2007; Trivitayanurak et al., 2008; Lee et al., 2009). We calculate CCN concentrations at two fixed supersaturations of 1.0 and $0.2 \%$, representative of convective and stratiform clouds. A comprehensive form of Köhler theory (Raymond and Pandis, 2003) is employed via look-up tables that take particle composition as input and yield critical activation diameters at various supersaturations as output for every combination of particle compositions. We do not consider the effects of surfactants on the Kelvin effect and CCN formation (Facchini et al., 1999).

$\mathrm{CCN}(0.2 \%)$ and $\mathrm{CCN}(1.0 \%)$ are both calculated for every nucleation simulation in this work. Concentrations are calculated both spatially (latitude and longitude) and zonally averaged (latitude and atmospheric pressure/altitude). We then take percent differences between the $\mathrm{CCN}$ concentrations for each simulation and the concentrations for the NONUC control simulation.

\subsubsection{Secondary organic aerosol}

We use the simple (SOA) fixed yield approach in which SOA is considered to be essentially non-volatile and does not thermodynamically partition between the vapor and condensed phase, which has been shown to be a better approximation for representing the growth of ultrafine particles (Pierce et al., 2011; Riipinen et al., 2011; D' Andrea et al., 2013). SOA is essentially a "pseudo-primary" source in TOMAS, calculated as $10 \%$ of modeled monoterpene emissions. The globally averaged flux using this approach is approximately $19 \mathrm{Tg} \mathrm{yr}^{-1}$, which is on the low end of estimated SOA fluxes (Goldstein and Galbally, 2007; Heald et al., 2011; Spracklen et al., 2011) Similar to sulfuric acid condensation, SOA condenses to all particles based on their Fuchs surface area (Pandis et al., 1991). Despite strong evidence for the partitioning of semi-volatile organic aerosols between the gas and particle phase (Donahue et al., 2006), the SOA treatment used here is simple and performed well in earlier nucleation studies that compared to observed aerosol number concentrations and growth rates (Riipinen et al., 2011, Pierce et al., 2011, Westervelt et al., 2013) and is not inconsistent with equilibrium partitioning if low-volatility organics are formed quickly (Donahue et al., 2011).

Recent studies have pointed to a large missing source of SOA in global models, perhaps anthropogenic or anthropogenically controlled in nature (Heald et al., 2011; Spracklen et al., 2011). As a result, we include a series of eight more simulations in which $100 \mathrm{Tg} \mathrm{yr}^{-1}$ of an additional SOA precursor is emitted at locations coincident with anthropogenic $\mathrm{SO}_{2}$ emissions (Spracklen et al., 2011; D’Andrea et al., 2013). The generic precursor has a timescale of $12 \mathrm{~h}$ until it forms SOA with unit yield in the condensed phase. Although this is a simple approach, it is sufficient enough for our purposes in testing the sensitivity of $\mathrm{CCN}$ concentrations from nucleation.

\subsection{Nuclei fate analysis}

We output one year of size distribution data from the model every 30 minutes from the model grid cell corresponding to Hyytiälä, Finland and calculate nucleation-relevant parameters in as in Westervelt et al. (2013), which evaluated the global model using many of the same parameters. In Westervelt et al. (2013), the model showed good agreement with observations, as average growth and nucleation rates, survival probabilities, and $\mathrm{CCN}$ formation rates were biased by less than $50 \%$.

We refer the reader to Westervelt et al. (2013) for details, but briefly, the nucleation and growth rates are based on a single-day analysis first outlined in Dal Maso et al. (2005). The nucleation rate, $J_{3}$, is a number balance between the rate of formation of nucleation mode particles and losses of those particles due to coagulation and growth out of the size range. For purposes of the nucleation rate calculation, we define the 
a

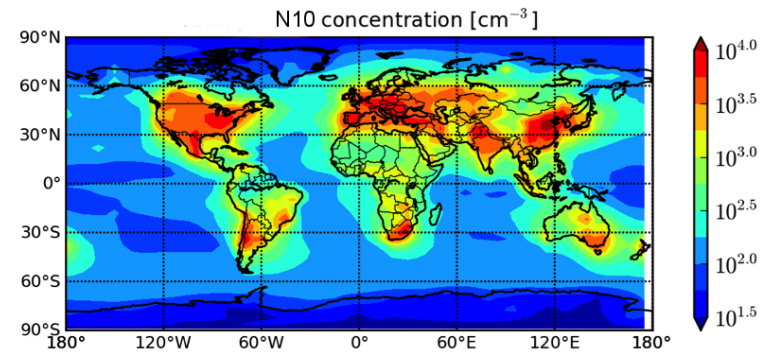

b

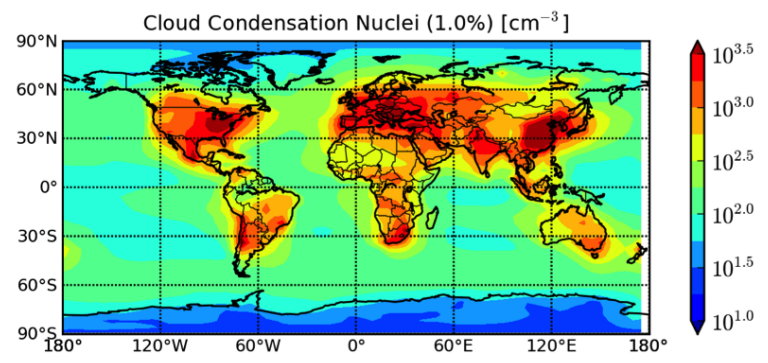

C

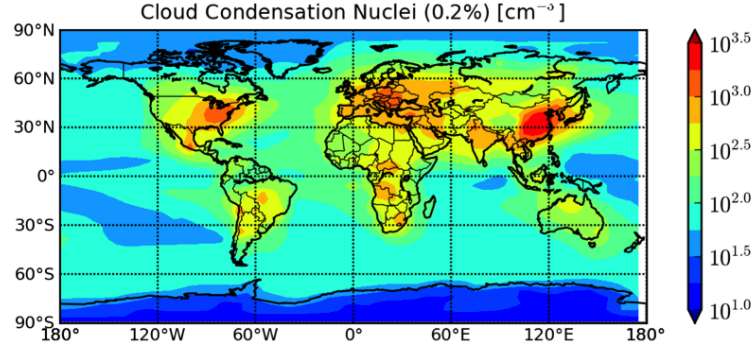

Figure 1. Annual-average boundary layer global distribution of $N_{10}$ (a), $\mathrm{CCN}(1.0 \%)(\mathbf{b})$, and $\mathrm{CCN}(0.2 \%)$ (c) for the ternary simulation with a $10^{-5}$ tuning factor (TER5 simulation).

nucleation mode as the 3-25 $\mathrm{nm}$ size range. Diameter growth rates are also calculated for the $3-25 \mathrm{~nm}$ range as well as a $25-100 \mathrm{~nm}$ range that is used for the survival probability calculation. Growth rate (GR) is the rate of change in size (diameter) over time during a nucleation and growth event (see Fig. 2 of Westervelt et al., 2013).

Two important quantities for particle and vapor loss, which partially determine $\mathrm{CCN}$ sensitivity to nucleation, are the coagulation sink and condensation sink. The coagulation sink, CoagS (units of $\mathrm{s}^{-1}$ ), of particles of size $i$ to a larger size $j$ is dependent on a coagulation coefficient $\left(K_{i j}\right)$ and the number concentration in the larger size range, $N_{j}$ (Eq. 1). In our calculations, we calculate coagulation coefficients for all particles larger than size $i$. The coagulation coefficient is based on Fuchs equation (Seinfeld and Pandis, 2006).

$\operatorname{CoagS}_{i}=\frac{1}{2} K_{i i} N_{i}+\sum_{j=i+1}^{\max } K_{i j} N_{j}$

The condensation sink ( $\mathrm{CS}$, also units of $\mathrm{s}^{-1}$ ) is proportional to the aerosol surface area in the kinetic regime and particle diameter in the continuum regime. It describes the first- order rate of uptake of sulfuric acid and/or other condensable vapors to aerosols (Eq. 2). In Eq. (2), $D$ refers to the gasphase diffusion constant, $D_{\mathrm{p} i}$ is the particle diameter in size bin $i, N_{i}$ is the number concentration in size $i$, and $\beta_{i}$ is the non-continuum correction factor, which is a function of the Knudsen number (Seinfeld and Pandis, 2006).

$\mathrm{CS}=2 \pi D \sum_{i=1}^{\max } \beta D_{\mathrm{p} i} N_{i}$

Calculation of survival probability is adapted from the Probability of Ultrafine Growth (PUG) theory, introduced by Pierce and Adams (2007). We define survival probability as the ratio of particle formation rates at the initial point of growth (typically $J_{3}$ ) and the $\mathrm{CCN}$-relevant size or endpoint of growth ( $J_{n}$, with $n=50$ or $100 \mathrm{~nm}$ typically). It is calculated according to Eq. (3) below (see also Eqs. 4-6 in Westervelt et al. 2013). It is a highly time and size resolved method that involves calculating timescales of condensation growth and coagulation loss at each step in the growing nucleation mode. The formation rate of $100 \mathrm{~nm}$ particles $\left(J_{100}\right)$ is calculated as the $3 \mathrm{~nm}$ formation rate multiplied by the survival probability from 3 to $100 \mathrm{~nm}$ (Eq. 4). Likewise, $J_{50}$ is calculated as $J_{3}$ multiplied by the survival probability to $50 \mathrm{~nm}$. These two particle sizes are within the range of typical activation diameters for $\mathrm{CCN}$ concentrations.

$\mathrm{SP}_{m, n}=\prod_{k=m}^{n-1} \exp \left(-\frac{\tau_{k, k+1}^{\text {cond }}}{\tau_{k}^{\text {coag }}}\right)$

$J_{n}=\mathrm{SP}_{3-n} J_{3}$

We extend our survival probability calculation beyond the end of the first day and estimate a multi-day survival probability. This estimate extrapolates the $25-100 \mathrm{~nm}$ growth rate and coagulational loss rates at the end of the growth period and applies it to subsequent days, allowing particles to either grow to $\mathrm{CCN}$ sizes or be lost via coagulation at a later time. We judge that the multi-day survival probability estimate probably overstates the ultimate $\mathrm{CCN}$ formation for several reasons. First, while real nuclei do not grow as quickly overnight but are lost to coagulation, we extrapolate the daytime growth rate for all subsequent hours, day or night. Second, it is expected that growth rates on nucleation days are somewhat higher than average. Third, it is expected that the coagulation sink on nucleation days is somewhat lower than average (Gong et al., 2010; Wu et al., 2011). As air masses have often shifted over a given location on days after nucleation days, it is difficult to track explicitly the actual evolution of the growing nucleation mode after the first day. Thus, this extrapolation method allows us to better estimate the growth to sizes beyond what is reached in the first day. 


\subsection{Simplified model for dependence of survival probability on condensation sink}

In addition to the methods described in Sect. 2.3, the survival probability can also be represented in another way based on simple scaling arguments, which we will make use of in Sect. 3.2.3. Here we propose a simple model that will be used to explain how changes in coagulation and condensation result in decreases in survival probability. We start with the theory presented by Lehtinen et al. (2007) for survival probability.

$\mathrm{SP}_{i-x}=\frac{J_{x}}{J_{i}}=\exp \left(-\gamma \cdot d_{i} \cdot \frac{\operatorname{CoagS}\left(d_{i}\right)}{\mathrm{GR}}\right)$

$\gamma=\frac{1}{m+1}\left[\left(\frac{d_{x}}{d_{i}}\right)^{m+1}-1\right]$

Equations (5) and (6) from Lehtinen et al. (2007) are an updated form of the original equations in Kerminen and Kulmala (2002). In the equations, $d_{i}$ and $d_{x}$ are the initial and final particle diameters (e.g., $3-100 \mathrm{~nm}$ ), CoagS is the coagulation sink, GR is the growth rate, $J_{i}$ is the particle nucleation rate at reference size $i, J_{x}$ is the eventual formation rate of larger, $\mathrm{CCN}$-sized particles from those nuclei, $\gamma$ is a parameter that accounts for size-dependent coagulation as the particle grows from initial to final sizes, $m$ is a constant that ranges between -1 and -2 (see Lehtinen et al., 2007 for details), and SP is survival probability. Leaving aside the $\gamma$ parameter, the exponential decay of particles predicted by Eq. (5) may be understood as follows. The time it takes for a fresh nucleus to grow to its final size is inversely proportional to the growth rate, GR. Over this time, a first-order loss of particles due to coagulation occurs with frequency, CoagS.

Recognizing that the coagulation and condensation sinks are linearly correlated (Lehtinen et al., 2007) (see also Sect. 3.2.3 below) while the growth rate and the condensation sink are linearly anti-correlated (since, assuming steadystate, the concentrations of condensable vapors are inversely proportional to the condensation sink), we can simplify Eqs. (5) and (6). For given bounds in the survival probability calculation, Eqs. (5) and (6) can now be written as solely a function of the CS (Eq. 7).

$\mathrm{SP}=\exp \left(-a \mathrm{CS}^{2}\right)$

Equation (7) shows the basic form of the inferred relationship between survival probability and condensation sink. This equation is similar to Eq. (A7) in McMurry et al. (2005), which related the particle survival probability $(\mathrm{P})$ to the ratio between CS and GR. Here, we have simply taken one step further, noting that the GR (growth rate) is inversely proportional to CS, yielding an expression for SP as a function of CS and the constant $a$ that depends on the initial and final particle diameters and the relationships between CoagS, GR, and CS. We note, however, that the GR is also proportional to the production rate of condensable vapors. If this production rate varies widely between nucleation events, this simplified model for the survival probability will not generally yield good predictions. It is also possible that the same sources that add to the vapor production rate also may contribute to condensation sink, adding another source of uncertainty in the simple model. However, to the extent that this simple formulation captures the actual changes in survival probability predicted by the full model (where vapor production does contribute to condensation sink), we can conclude that this effect is small. We will show later that this model does generally fit our full survival-probability calculations well and that variability in the production rate of condensable vapors is relatively minor in GEOS-Chem-TOMAS.

\section{Results}

Global maps of $N_{10}, \mathrm{CCN}(1.0 \%)$, and $\mathrm{CCN}(0.2 \%)$ for the TER5 simulation are shown in Fig. 1. All maps and figures, except for Fig. 4, only include the base case $19 \mathrm{Tg} \mathrm{yr}^{-1}$ SOA source and do not include the $100 \mathrm{Tg} \mathrm{yr}^{-1}$ anthropogenically enhanced SOA source. Westervelt et al. (2013) showed that the TER5 nucleation mechanism performed well against observed nucleation rates, growth rates, particle survival probabilities, and $\mathrm{CCN}$ formation efficiency from several field-campaign sites with biases within $50 \%$ for all metrics. Thus, the TER5 simulation is shown here as a possible "best guess" to CCN and number concentrations. In Fig. 1, annually averaged $N_{10}$ concentrations are highest over the continents, with specific hotspots in eastern North America, western Europe, and China. $\mathrm{CCN}(1.0 \%)$ and $\mathrm{CCN}(0.2 \%)$ generally follow the same pattern, although with lower concentrations. $\mathrm{CCN}(0.2 \%)$ are less abundant than $\mathrm{CCN}(1.0 \%)$, which is expected due to the larger diameter required for activation at $S=0.2 \%$.

\subsection{Global sensitivity of $N_{10}$ and $\mathrm{CCN}$ to nucleation}

Figure 2 shows the percent change in annually averaged $N_{10}$ for a selection of the sensitivity simulations (as listed in Table 2) compared to the base case simulation in which nucleation is turned off (NONUC). Both boundary layer spatial distributions (left column) and zonal averages (right column) are shown. Table 3 shows the global, annual average percent changes for each of the sensitivity simulations. The $N_{10}$ percent differences between the binary and the NONUC simulations, as seen in panels a and b of Fig. 2, are quite small in the boundary layer. In fact, there are some regions of percent decrease in $N_{10}$, such as off the western coast of South America. The reason for this decrease is likely due to the demand for condensable vapors by nucleated particles that are lost by coagulation to larger particles before they grow to $10 \mathrm{~nm}$. 

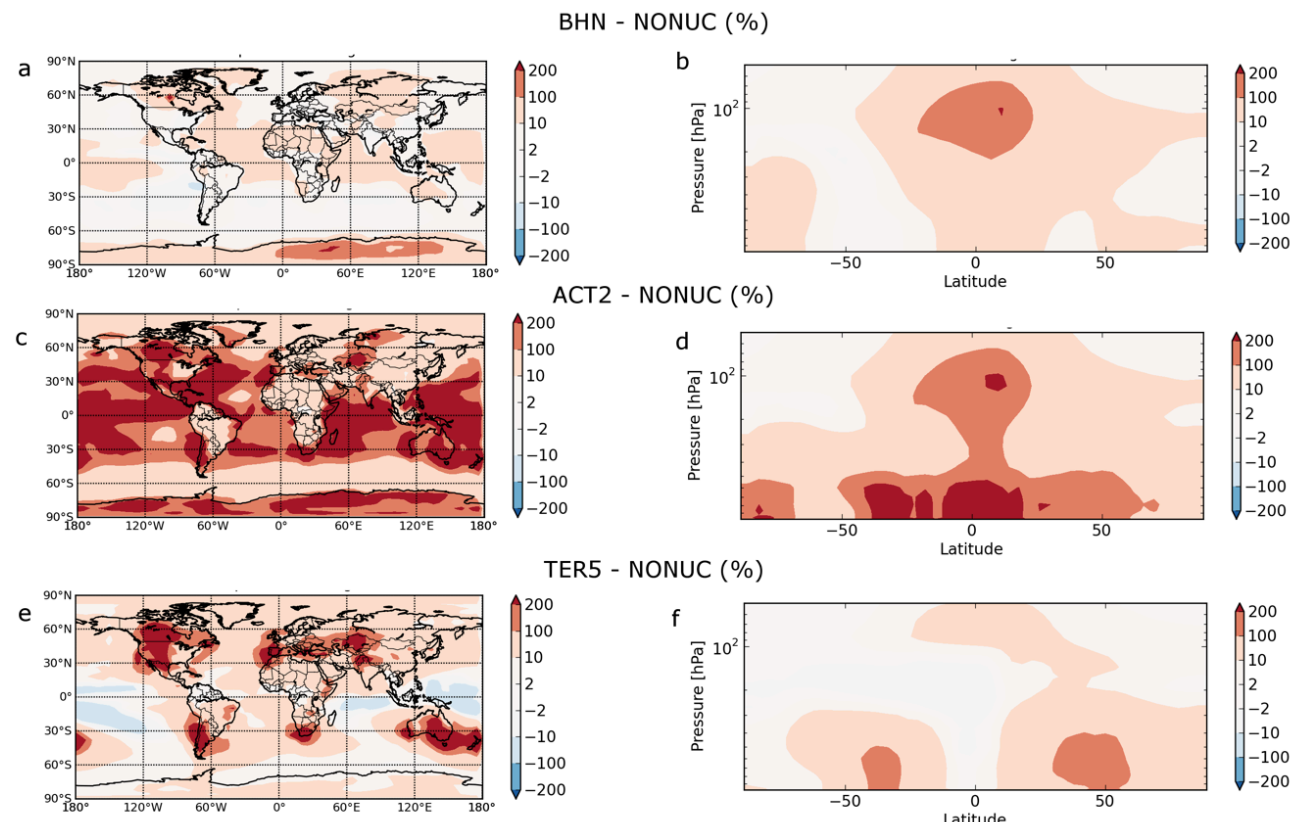

TER5 - NONUC (\%)
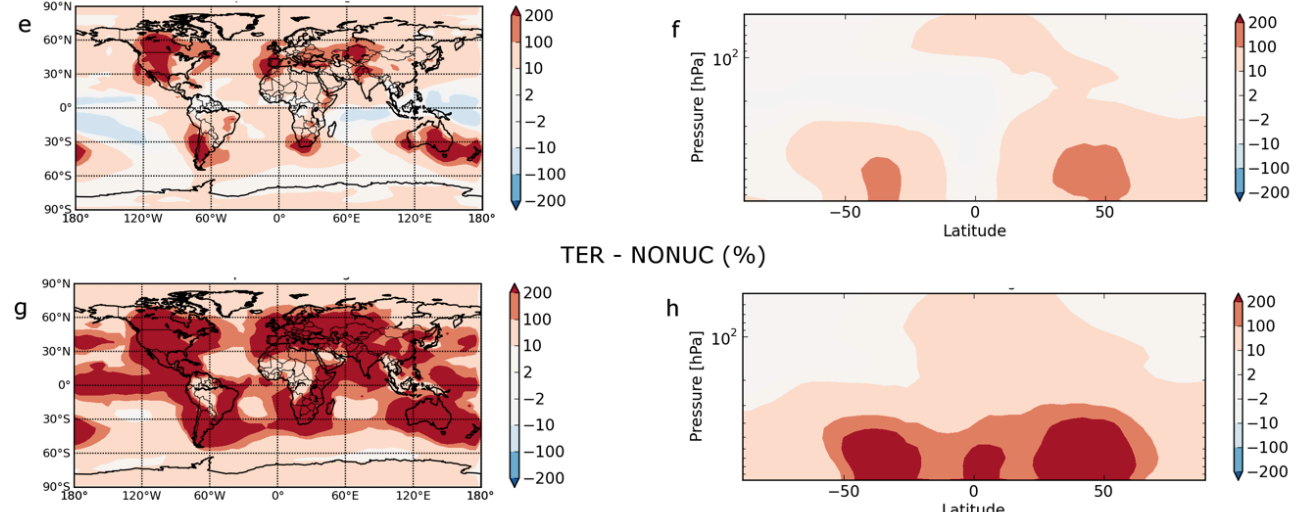

TER - NONUC (\%)

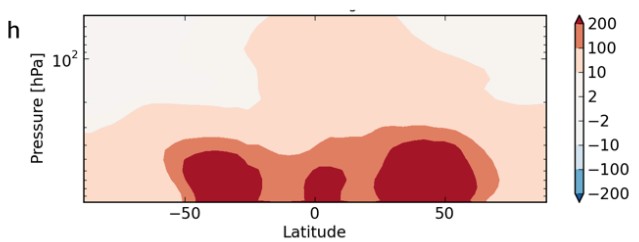

Figure 2. Global percent change in total particle number concentration $\left(N_{10}\right)$ surface and zonal plots. Color contours in all panels represent the percent change in number concentration between the listed nucleation simulations and the simulation with nucleation off: (a, b) binary; (c, d) Activation $\left(A=2 \times 10^{-6}\right)$; (e, f) Ternary $\left(10^{-5}\right.$ factor $)$; (g, h) Ternary.

Table 3. Global-average percent increases in a given nucleation simulation compared to a simulation with no nucleation. Values are averaged for boundary layer only. See also Figs. 2-3.

\begin{tabular}{lrcc}
\hline & $N_{10}(\%)$ & $\mathrm{CCN}(1.0 \%)(\%)$ & $\mathrm{CCN}(0.2 \%)(\%)$ \\
\hline BHN & 23 & 27 & 49 \\
ION & 55 & 50 & 60 \\
ACT1 & 140 & 79 & 66 \\
ACT2 & 170 & 88 & 69 \\
TER5 & 48 & 46 & 56 \\
TER3 & 103 & 70 & 64 \\
TER & 190 & 99 & 78 \\
\hline
\end{tabular}

This demand for condensable vapor limits the ability of the primary particles to grow and survive.

Figure $2 \mathrm{~b}$ shows that while the binary nucleation parameterization of Vehkamäki et al. (2002) does not produce a large fractional increase in $N_{10}$ in the boundary layer, it does have a more pronounced fractional effect in and around the tropical upper troposphere.

Figure $2 \mathrm{c}$ and $\mathrm{d}$ show the percent changes for the ACT2 simulation. The ACT1 maps are not shown but are similar to ACT2. One major characteristic of the ACT2 simulation is that the activation mechanism predicts a large enhancement of $N_{10}$ in the boundary layer, especially over the oceans where increases from nucleation may not be expected. This is partially due to the activation simulation lacking a third nucleating species that helps regulate whether or not nucleation occurs in certain environments. For example, in TER simulations, low amounts of ammonia over the oceans prevent nucleation from occurring. The zonal plot shows the strong $N_{10}$ enhancements near the surface. Above about $400 \mathrm{hPa}$, the binary nucleation scheme (same as in the BHN simulation), which is also used in the ACT2 simulation, dominates the $N_{10}$ increases, as evidenced by the similarities in panels b and d.

Panels e and f (Fig. 2) show the percent enhancements for TER5. TER3 is omitted here due to the spatial patterns being similar (albeit with different intensities in particle number concentration). The TER5 simulation gets similar $N_{10}$ increases across the continents as ACT2, but without the large increases over the oceans. The nucleation contribution to $N_{10}$ is larger near the surface and decreases in importance with altitude. 

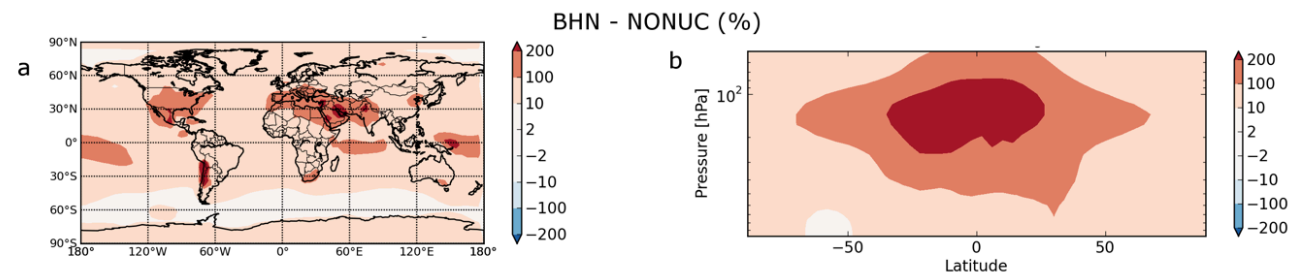

ACT2 - NONUC (\%)
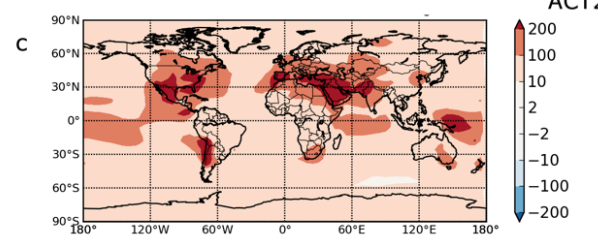

d

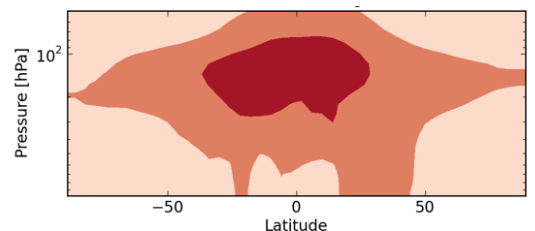

TER5 - NONUC (\%)

e ${ }_{6}^{9}$
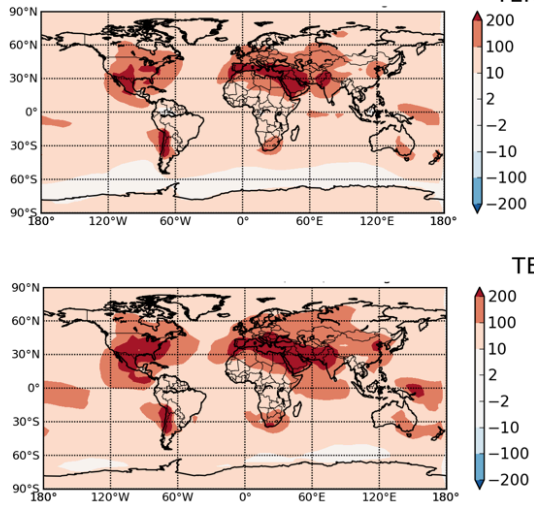

$\mathrm{f}$

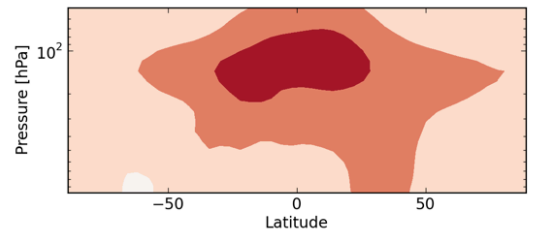

R - NONUC (\%)

$$
\mathrm{h}
$$

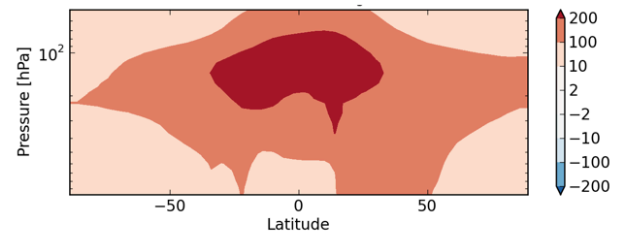

Figure 3. Global cloud condensation nuclei concentration at $S=0.2 \%(\mathrm{CCN}(0.2 \%))$ percent change surface and zonal plots. Color contours in all panels represent the percent change in number concentration between the various nucleation simulations and the simulation with nucleation off: (a, b) binary; (c, d) Activation $\left(A=2 \times 10^{-6}\right)$; (e, f) Ternary $\left(10^{-5}\right.$ factor); (g, h) Ternary.

Panels g and h (Fig. 2) show the enhancements for TER. Past results have found overprediction in nucleation rates and $N_{10}$ concentrations when using the ternary parameterization without a scaling factor (Jung et al., 2010). Not surprisingly, the largest continental enhancements occur in the TER sensitivity simulation. It is interesting to note, however, that TER is not the highest simulation in $N_{10}$ enhancements over the ocean (ACT2 has the larger contribution) due to the generally low concentrations of ammonia over the oceans in the model.

Figure 3 is the same as Fig. 2 except the enhancements are calculated for $\mathrm{CCN}(0.2 \%)$ instead of $N_{10}$. Figure 3 shows that in most polluted regions of the world, all nucleation schemes we simulated at least double the number of $\mathrm{CCN}$ compared to the NONUC simulation. Interestingly, the $\mathrm{CCN}(0.2 \%)$ spatial maps across the four sensitivity studies are all relatively similar and uniform, with exceptions mostly in the Middle East and the southern United States. The uniformity between the different nucleation mechanisms suggests that the influence of each specific nucleation scheme is only moderately important. There are no instances of decreases in either the spatial distributions or the zonal plots.
The BHN scenario (Fig. 3a and b) has a weak relative increase in boundary layer $N_{10}(23 \%$ global average, see Table 3), yet has a larger relative increase for boundary layer $\mathrm{CCN}(1.0 \%)-(27 \%)$ and $\mathrm{CCN}(0.2 \%)-(49 \%)$. Although seemingly counterintuitive, this is due to nucleation aloft in the free troposphere and subsequent growth to larger sizes during downward subsidence before entraining into the boundary layer. Thus, the absolute increases in $N_{10}$ and $\mathrm{CCN}(0.2 \%)$ in the boundary layer are similar because a large fraction the nucleated particles are $\mathrm{CCN}(0.2 \%)$ sizes by the time they reach the boundary layer (and the boundary layer $\mathrm{CCN}(0.2 \%)$ concentrations are lower than the boundary layer $N_{10}$ concentrations). However, because the $\mathrm{CCN}(0.2 \%)$ concentrations are $\sim 10 \times$ lower, the relative enhancement of $\mathrm{CCN}(0.2 \%)$ in the boundary layer are $\sim 10 \times$ larger. When averaging through the entire troposphere, the $N_{10}$ increase is larger than both $\mathrm{CCN}(1.0 \%)$ and $\mathrm{CCN}(0.2 \%)$, as is expected. This implies that at least in the BHN scheme, nucleation in the free troposphere can be a major source of $\mathrm{CCN}$ in the boundary layer, which has also been observed in the GLOMAP model (Merikanto et al., 2009).

The ACT2 simulation, shown in Fig. $3 \mathrm{c}$ and $\mathrm{d}$, has stronger $\mathrm{CCN}(0.2 \%)$ enhancements in some regions across 

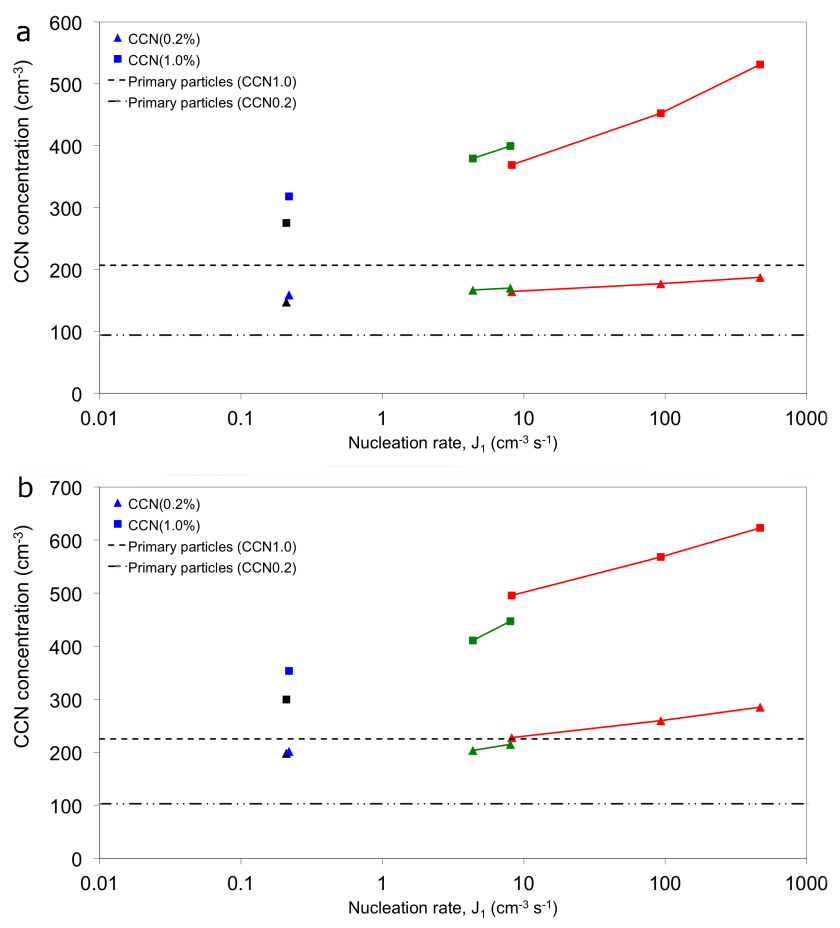

Figure 4. Global average cloud condensation nuclei concentrations in the boundary layer for all nucleation simulations. Squares represent $\mathrm{CCN}(1.0 \%)$, and triangles show $\mathrm{CCN}(0.2 \%)$. Panel (a) shows the base SOA simulation results while (b) shows the high SOA simulation results (extra $100 \mathrm{Tg} \mathrm{yr}^{-1}$ ). In both panels, the dashed black lines represent the $\mathrm{CCN}(1.0 \%)$ concentrations for the simulation with no nucleation (nominally, primary particle contribution). The dash-dot black lines show the same for $\operatorname{CCN}(0.2 \%)$. Blue lines refer to ion nucleation, black is binary, green is activation, and red is ternary.

the boundary layer compared to the BHN simulation. Since the ACT2 simulation is coupled with BHN, we see large increases in $\mathrm{CCN}(1.0 \%)$ and $\mathrm{CCN}(0.2 \%)$ (see Table 3 ) even in the free troposphere. In these simulations, $\mathrm{CCN}$ enhancement is due to both effects of BHN as described above as well as the boundary layer enhancement provided by the activation simulation.

The TER5 boundary layer and zonally averaged plots, seen in Fig. 3e and f, look similar to ACT2. However, the TER5 simulation has less of a pronounced increase across the Pacific Ocean in between the tropics. As a result, TER5 has a slightly smaller $\mathrm{CCN}$ percent increase when compared to ACT2 (see Table 3). Unlike binary nucleation, ternary nucleation is dominant in the boundary layer and weak in the free troposphere. The boundary layer average percent increase in $\mathrm{CCN}(0.2 \%)$ is $56 \%$, confirming some importance of boundary layer nucleation for TER5. Finally, the TER simulations have the strongest $\mathrm{CCN}$ enhancements for the boundary layer, as seen in Fig. $2 \mathrm{~g}$ as well as Table 3 due to the unrealistically high nucleation rates in these simulations (see Fig. 4).
In all of the results plotted in Figs. 2 and 3, it appears that the fractional $\mathrm{CCN}(0.2 \%)$ increase in the free and upper troposphere (up to $200 \mathrm{hPa}$ ) is larger than the $N_{10}$ enhancement. Although physical explanations such as aerosol transport through deep convection are plausible, this is likely an artifact of the differencing against the control simulation, NONUC. Without nucleation active (in the NONUC simulation), there is no particle source in the tropical free troposphere and thus $\mathrm{CCN}(0.2 \%)$ concentrations are small (sometimes less than 10 particles $\mathrm{cm}^{-3}$ ). Thus, a small addition of particles due to nucleation in the various simulations can lead to large relative increases. The addition of $N_{10}$ from the nucleation-active simulations is compared against a relatively higher $N_{10}$ control value than is expected. In summary, globally averaged $\mathrm{CCN}(0.2 \%)$ increases range from about 49 to $78 \%$ for the boundary layer above the NONUC case. The TER5 simulation, which has performed well against observations, had a $56 \%$ increase in boundary layer-averaged $\mathrm{CCN}$ compared to a simulation without nucleation active, but this enhancement only increases to $78 \%$ for a much faster nucleation scheme (TER). The range of these increases is small considering the nucleation rates varied by as many as 4 orders of magnitude, as seen in Fig. 4 and discussed below.

Figure 4 shows globally averaged $\mathrm{CCN}(0.2 \%)$ and $\mathrm{CCN}(1.0 \%)$ concentrations against tropospheric average nucleation rates $\left(J_{1}\right)$. The NONUC control simulation gives us a rough estimate of the primary $\mathrm{CCN}$, which is represented by the dashed black lines for comparison. For the base SOA simulation (panel a), primary $\mathrm{CCN}(0.2 \%)$ are roughly $100 \mathrm{~cm}^{-3}$ globally averaged, whereas $\mathrm{CCN}(1.0 \%)$ are about twice that. Consistent with the global map results shown in Figs. 2 and 3, $\mathrm{CCN}(0.2 \%)$ do not appear to be very sensitive to large changes in the nucleation rate. Specifically, the black and blue triangles in Fig. 4, representative of the BHN and ION simulations, respectively, are about 4 orders of magnitude lower in the nucleation rate that the TER simulation (furthest right red triangle). However, the $\mathrm{CCN}(0.2 \%)$ increases from the BHN to TER cases are comparatively small at 40 particles $\mathrm{cm}^{-3}$, or a $29 \%$ increase. On the other hand, the slowest nucleation mechanism, BHN, gives a global boundary layer enhancement of $49 \%$ over the NONUC simulation. From this, we conclude that the details of a particular nucleation theory seem to be less important than the use of any theory within the global model for predicting $\mathrm{CCN}(0.2 \%)$. Although this $29 \%$ sensitivity to nucleation mechanism is not insignificant enough to ignore, it is important to note that it is smaller than the sensitivity between any nucleation mechanism compared to a no-nucleation case. The insensitivity is also evidenced by the green solid lines, which represent the two activation cases (ACT1 and ACT2), and the red solid lines, which signify TER5, TER3, and TER. Both of these lines are relatively flat for $\mathrm{CCN}(0.2 \%)$, indicating a small increase in $\mathrm{CCN}$ for a large increase in nucleation. Additionally, the $29 \%$ cited above represents the largest possible range in $\mathrm{CCN}$ changes. Although no nucleation mechanism 
is without faults, the $\mathrm{CCN}(0.2 \%)$ sensitivity between two more reasonable nucleation simulations (for example, TER3 and TER5) is much smaller (less than 10\%).

As expected, $\mathrm{CCN}(1.0 \%)$ is more sensitive to changes in nucleation rate, as evidenced by the steeper slopes in the $\mathrm{CCN}(1.0 \%)$ data (square markers). For example, between the TER5 and TER simulation, roughly a two orderof-magnitude increase in the nucleation rate results in a 200 particles $\mathrm{cm}^{-3}$ increase in the $\mathrm{CCN}(1.0 \%)$ concentrations. The ACT1 and ACT2 simulations also show an increased CCN sensitivity to the same changes in nucleation. The difference in globally averaged nucleation rate between BHN and ION is only about $0.01 \mathrm{~cm}^{-3} \mathrm{~s}^{-1}$, but the change in $\mathrm{CCN}(1.0 \%)$ is 70 particles $\mathrm{cm}^{-3}$. This difference is likely due to differences in the spatial dependence of nucleation. For these two simulations, the specific nucleation mechanism does matter, since BHN and ION result in very similar nucleation rates but different CCN. This implies that in regions where ION nucleation dominates, the survival probabilities are higher than in regions where BHN dominates, on average. In particular, the mid-to-upper troposphere has the largest differences between BHN and ION in CCN concentrations (not shown). This is consistent with recent work suggesting ion-based nucleation may be relevant in the upper troposphere regions where colder temperatures prevail (Kirkby et al., 2011). Although the sensitivities are low for most of the other simulations, the mechanisms are still important for other reasons, such as spatial and temporal variability. Spatial effects are clearly important as seen in the ACT2 and TER5 simulations in which ACT2 predicts large $N_{10}$ and $\mathrm{CCN}(0.2 \%)$ enhancements over the oceans (Figs. 2 and 3). Additionally, although aerosol indirect forcing cannot be estimated with the current model setup, nucleation impacts on aerosol forcing are likely larger in certain regions. Future work should seek to explore the sensitivity of forcing to nucleation. It also appears that mechanisms matter for seasonal and daily variability in nucleation event frequency, growth rates, nucleation rates, survival probabilities, and CCN formation (see Figs. 8 and 9 and Sect. 3.2.2, and Westervelt et al., 2013).

Finally, we include CCN-nucleation rate results in Fig. 4 for the same nucleation mechanisms but with an extra $100 \mathrm{Tg} \mathrm{yr}^{-1}$ of SOA available for condensation (panel b). We find that these cases (using the same color and symbol scheme as the base SOA simulations) result in higher $\mathrm{CCN}(1.0 \%)$ and $\mathrm{CCN}(0.2 \%)$, due to the increased condensational growth. For $\mathrm{CCN}(0.2 \%)$, the change between low and high SOA simulations increases as the nucleation rate increases. In other words, specifically for the TER5-TER3TER line, the slope of the high SOA line (red in panel b) is greater than the slope of the low SOA line (panel a). This suggests that the additional SOA is able to grow nucleated particles to $\mathrm{CCN}$ activation sizes that would not otherwise be activated and make survival probabilities less sensitive to changes in nucleation rates. However, the change in the slope

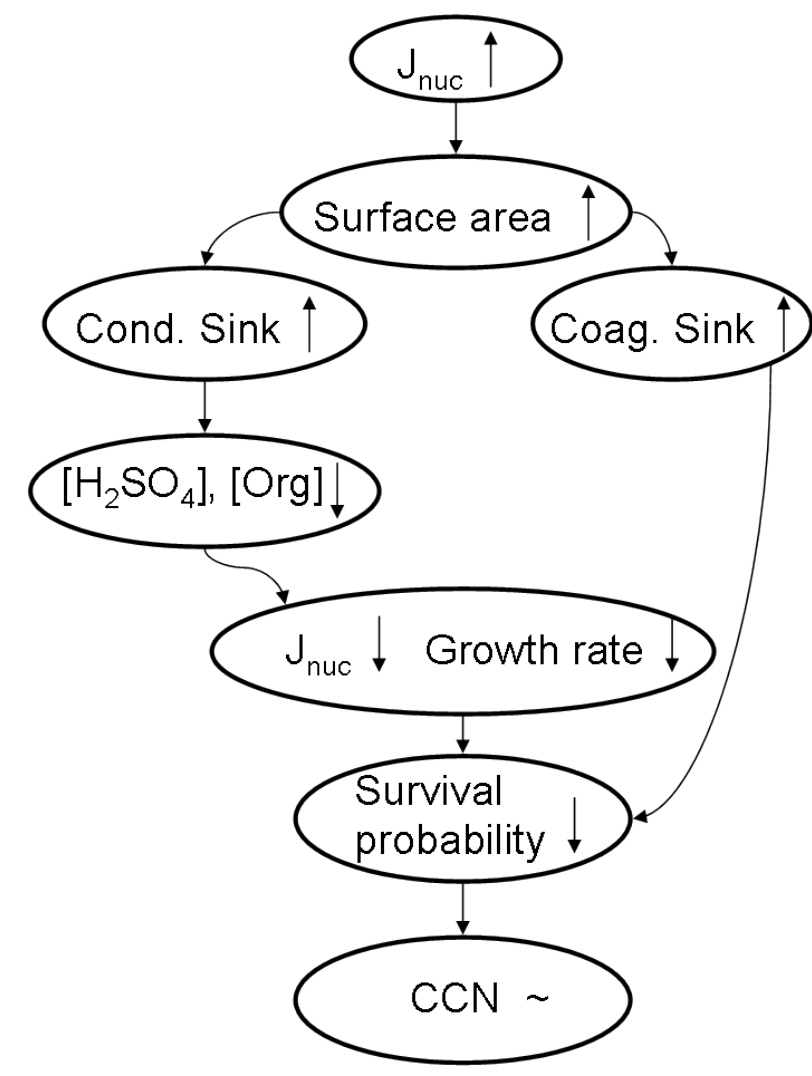

Figure 5. Flowchart of microphysical feedbacks that decrease survival probability with increasing nucleation rates, limiting the formation of CCN from nucleation events.

of $\mathrm{CCN}(1.0 \%)$ is small because nucleated particles require less growth to reach $\mathrm{CCN}(1.0 \%)$ sizes.

\subsection{Microphysical feedbacks responsible for lower survival probabilities at higher nucleation rates}

Despite introducing large differences in nucleation rates using the various parameterizations listed in Table 2, CCN concentrations are only modestly increased. Figure 5 shows qualitatively how an increase in the average nucleation rate in the model can ultimately cause a negative feedback loop that minimizes $\mathrm{CCN}$ changes. Larger nucleation rates increase the Fuchs aerosol surface area, which increases the coagulation and condensation sinks. The increased condensation sink reduces condensable vapor concentrations, which slows down particle growth. This slowed growth, in combination with increased coagulation, reduces the survival probability and limits $\mathrm{CCN}$ formation.

The following three sections (Sects. 3.2.1, 3.2.2, and 3.2.3) provide the quantitative evidence for the feedback phenomenon we have qualitatively described above. Small particles are not traditionally thought to have a large impact on aerosol surface area (Fuchs) due to the squaredependence on diameter. However, when considering that 
a

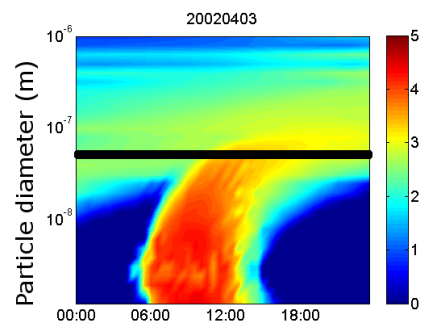

d

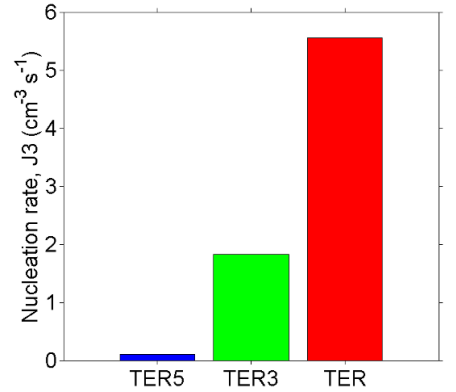

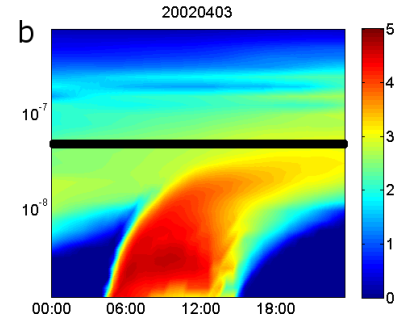

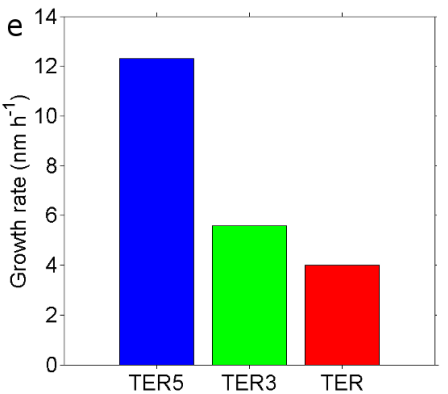

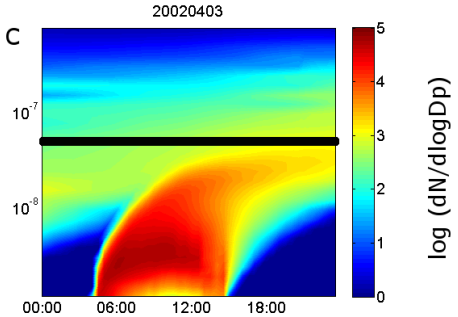

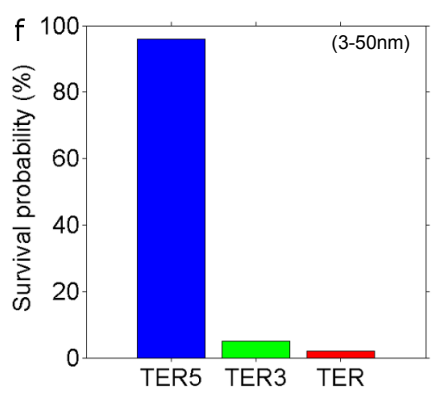

Figure 6. Nucleation metrics and number size evolution plots for 3 April 2002 (local time) at Hyytiälä. Panel (a) is the size distribution evolution for the TER5 simulation, panel (b) is the same for the TER3 simulation, and panel (c) is the TER simulation. The bottom row (panels $\mathbf{d}$ through $\mathbf{f}$ ) shows the nucleation rate, growth rate $(3-25 \mathrm{~nm})$, and survival probability to $50 \mathrm{~nm}$ (multi-day) for each of the three ternary nucleation scenarios. The heavy black line indicates the $50 \mathrm{~nm}$ size threshold used for this analysis.

modeled nucleation events are not isolated occurrences and can have compounding impacts that feedback on each other, the effect is significant enough to increase the condensation sink, especially when the growth of these nucleated particles to Aitken and accumulation modes is considered. There are two main reasons why nucleated particles can contribute to the aerosol surface area enough to buffer the CCN concentrations. First, with large increases in the nucleation rate, the CCN mode will shift to smaller sizes over the longterm of many nucleation events due to a larger presence of nucleated particles. This allows nucleated particles to contribute a larger fraction of surface area than they might otherwise without the nucleation rate enhancements. For constant aerosol mass production rates, an increase in $\mathrm{CCN}$ number concentration from nucleation leads to aerosol Fuchs surface area enhancements, much like how smaller and more numerous cloud droplets result in larger cloud surface area with a fixed water vapor budget (cloud albedo aerosol indirect effect or Twomey effect). Second, even in the short-term, for very high nucleation rates, there is a non-negligible surface area increase associated with fresh nuclei themselves. Figures 6-9 and the following sections will provide quantitative evidence for the increase in surface area and condensation sink due to increases in the average nucleation rate.

\subsubsection{Sample nucleation day}

We first present a case study of a single day: 3 April 2002 at Hyytiälä. The first row of Fig. 6 (panels a, b, and c) shows three similar plots of the number size distribution evolution in time ("banana plots"). Color contours represent the log- arithm (base 10) of the number size distribution function $\left(\log 10\left(\mathrm{~d} N / \mathrm{d} \log D_{\mathrm{p}}\right)\right)$. The initial background size distributions are different between the three simulations due to differences in nucleation, growth and survival probability and previous days (shown quantitatively in Fig. 7). The black line in each panel of Fig. 6 demarcates the $50 \mathrm{~nm}$ size threshold. Notice that within the first day, only the TER5 simulation (panel a), reaches the $50 \mathrm{~nm}$ size considered to be relevant for $\mathrm{CCN}$. In panels $\mathrm{b}$ and $\mathrm{c}$, the growing nucleation mode does reach the $50 \mathrm{~nm}$ size, but not until the second or third day after nucleation. Panel d shows the nucleation rate $\left(J_{3}\right)$ for each of the sensitivity cases for 3 April, panel e shows the mean growth rates, and panel f shows the survival probability to $50 \mathrm{~nm}$. As the nucleation rates increase from TER5 to TER3 and TER, both growth rates and survival probabilities decrease. This is not only due to feedbacks occurring during this particular event, but also includes feedbacks from previous nucleation events, as discussed previously. On this particular day, the survival probability is over $90 \%$ in TER5 and less than $10 \%$ in TER3 and TER.

Figure 7 shows the condensation sink over the course of the nucleation event and Fuchs surface area size distributions for the sample day at Hyytiälä. For all three ternary simulations, the overall condensation sink increases throughout the day (panel a) consistent with condensational growth of the particle size distribution. The TER and TER3 simulations have a short-lived enhancement in condensation sink that corresponds with the onset of the nucleation event; the same enhancement is not visible in the TER5 simulation. This indicates that at least under very high nucleation rates, there 


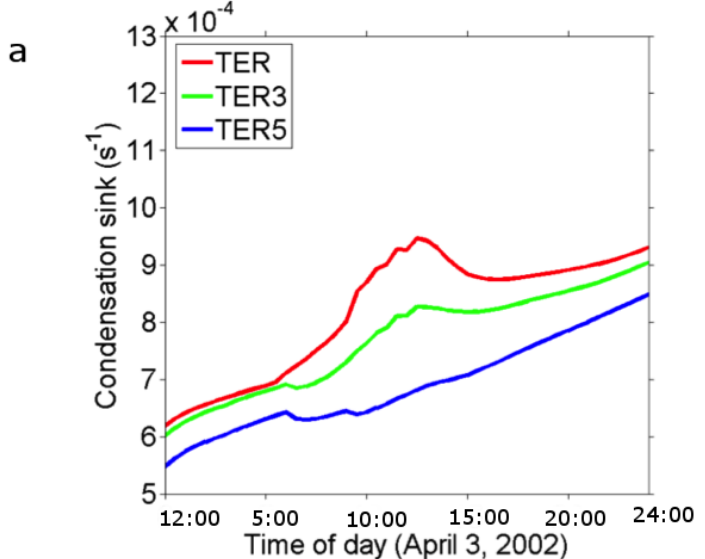

b

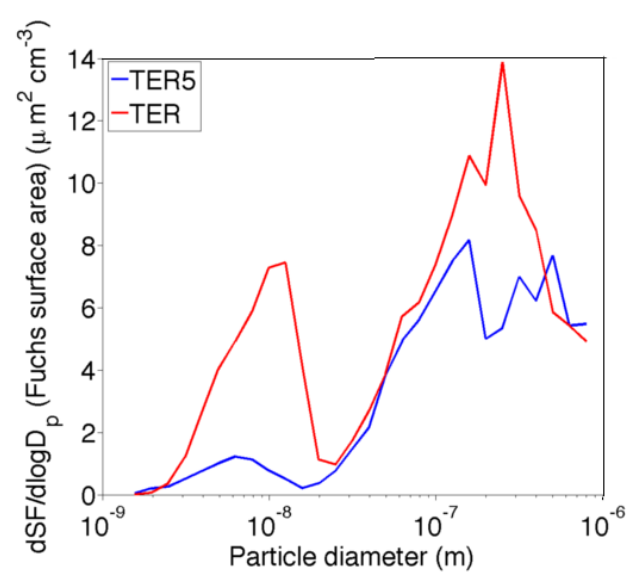

Figure 7. Visualization of condensation sink (a) and particle surface area size distribution (b), for 3 April 2002 at Hyytiälä. Fuchs surface area size distributions are shown for a 12:00 time slice in the nucleation event on 3 April 2002

is an immediate impact of nucleation on Fuchs surface area and condensation sink even if it is short lived. It can be seen in Fig. $7 \mathrm{~b}$ that, during the middle of the nucleation event, the nucleation mode (centered at $10 \mathrm{~nm}$ at 12:00) makes a significant contribution to Fuchs surface area, but this goes away after a few hours as these particles coagulate. It is also important to note that the condensation sink in the TER simulations starts and remains higher than both the TER3 and TER5, which shows that prior nucleation events in the longterm affect the initial condensation sink at the start of a new nucleation event. The reason for the higher starting condensation sink in the TER simulation is the same as described in the introduction: for a fixed budget of condensable aerosol mass, a higher particle concentrations imply a shift of the $\mathrm{CCN}$ model to smaller sizes and an increase in its surface area. This can be seen in Fig. 7b, where the accumulation mode Fuchs surface area is higher in TER5 compared to TER. Although Fig. 7b shows this for 12:00 during the event, the Fuchs surface area was already higher at the beginning of the day. Comparing the two more realistic nucleation rates,
TER 5 vs. TER3, this persistent increase in condensation sink is more important than the short-term contribution from the nucleation mode.

Finally, using the nucleation rate $\left(J_{3}\right)$ and (SP) to $50 \mathrm{~nm}$ we can calculate the $\mathrm{CCN}$ formation rate at $50 \mathrm{~nm}\left(J_{50}\right)$. For this particular event, the $J_{50}$ for TER5, TER3, and TER are $0.09,0.1$, and $0.11 \mathrm{~cm}^{-3} \mathrm{~s}^{-1}$, respectively. Despite order-ofmagnitude variation in nucleation rates, the decreased survival probabilities in TER and TER3 compensate for the differences, resulting in similar values of $\mathrm{CCN}$ formation rate. Although the fastest nucleation rates in the TER simulation lead to the largest $\mathrm{CCN}$ formation rates, these $\mathrm{CCN}$ formation rates are only marginally (10-20\%) larger than the slower nucleation cases, TER3 and TER5.

\subsubsection{Full year of nucleation events}

To further quantify the dampening of $\mathrm{CCN}$ changes to changes in nucleation, we expand our discussion with a yearlong time series of nucleation events in the TER5, TER3, and TER simulations at the sample location of Hyytiälä, Finland. The TER5 simulation was already considered in Westervelt et al. (2013), but we add in the TER3 and TER simulations to allow us to look at how incremental changes in the nucleation rates effect growth rates, coagulation sink (for $3 \mathrm{~nm}$ particles), condensation sink, survival probabilities, and ultimately $\mathrm{CCN}$ concentrations. Figure 8 shows cumulative distribution functions for the three ternary simulations at Hyytiälä. Panel a shows roughly order-of-magnitude increases in $J_{3}$ from the TER5 to TER3 to TER simulations (note that the nucleation rate scale factors are two and three orders of magnitude apart). This increase in nucleation causes an increase in both the coagulation and condensation sinks, which follow the same order of TER > TER3 > TER5 (panels c and d). Because of the enhancement of the condensation sink due to the increased Fuchs surface area from faster nucleation rates, condensable vapor concentrations are reduced. Because of the reduction in condensable vapor concentrations, the TER simulation has the slowest growth rates by as much as a factor of 2 (panel b). The TER5 simulation, on the other hand, has fast growth rates that allow particles to more effectively survive to $\mathrm{CCN}$ sizes (50 or $100 \mathrm{~nm}$ ) within one day, as was the case for the 3 April event shown above.

Figure 9 shows the cumulative distribution functions (CDF) for survival probabilities and $\mathrm{CCN}$ formation rates. Survival probabilities are calculated for multi-day growth, as is explained in Sect. 2.2.3 Because of the increased coagulation and condensation sink, particle survival to 50 or $100 \mathrm{~nm}$ (panels a and c) is diminished in the TER3 and TER simulations compared to the TER5. The survival probabilities tend to be quite sensitive to the growth rate changes seen in Fig. 8 . As a result, large increases in the nucleation rate (Fig. 8a) are offset by low survival probabilities (e.g., more than half the cases for TER have $<1 \%$ chance of surviving to grow to $100 \mathrm{~nm})$. As a result, the annual-mean $J_{50} \mathrm{CCN}$ formation 

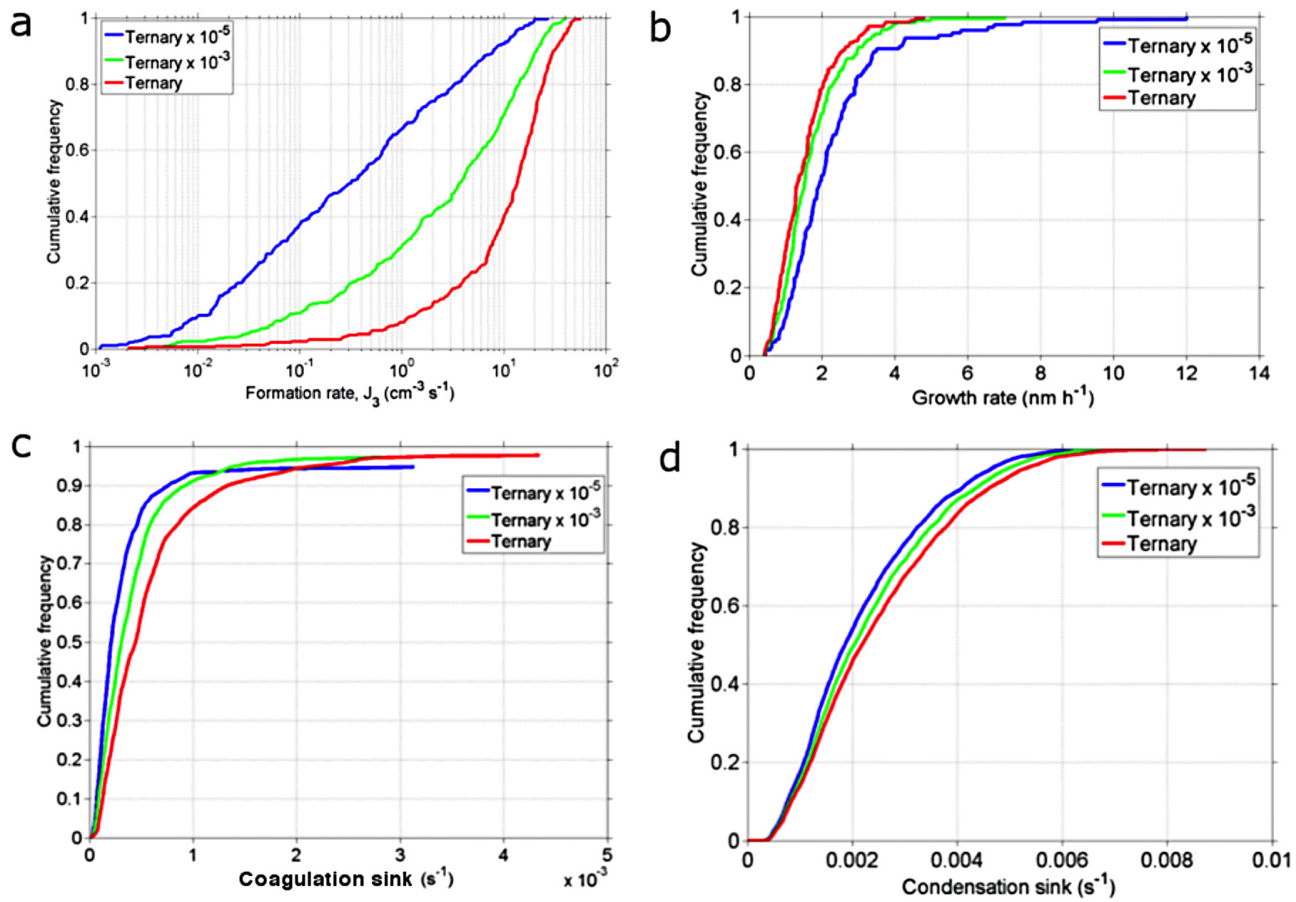

Figure 8. Cumulative distribution functions of nucleation event metrics at Hyytiälä. Red curves represent the original ternary simulation (Napari et al., 2002). Green curves represent ternary nucleation with a $10^{-3}$ tuning factor. Blue curves represent ternary nucleation with a $10^{-5}$ tuning factor. (a) $3 \mathrm{~nm}$ particle formation rate, $J_{3}\left(\mathrm{~cm}^{-3} \mathrm{~s}^{-1}\right)$; (b) $3-25 \mathrm{~nm}$ growth rate, GR (nm h ${ }^{-1}$ ); (c) Coagulation frequency $\left(\mathrm{s}^{-1}\right)$; (d) Condensation sink $\left(\mathrm{s}^{-1}\right)$.

Table 4. Mean and median values for the three ternary simulations at Hyytiälä for the multi-day survival probability calculation. Median values in parentheses.

\begin{tabular}{lrrr}
\hline & Ternary $\times 10^{-5}$ & Ternary $\times 10^{-3}$ & Ternary \\
\hline$J_{3}\left(\mathrm{~cm}^{-3} \mathrm{~s}^{-1}\right)$ & $2.3(0.3)$ & $7.4(3.7)$ & $15.1(13.6)$ \\
$\mathrm{GR}\left(\mathrm{nm} \mathrm{h}^{-1}\right)$ & $2.3(1.9)$ & $1.7(1.5)$ & $1.5(1.3)$ \\
$\mathrm{SP}_{50}(\%)$ & $37(36)$ & $12(14)$ & $4.9(4.5)$ \\
$J_{50}\left(10^{-2} \mathrm{~cm}^{-3} \mathrm{~s}^{-1}\right)$ & $7.1(6.0)$ & $7.2(7.0)$ & $7.4(8.0)$ \\
$\mathrm{SP}_{100}(\%)$ & $2.9(2.0)$ & $0.4(0.4)$ & $0.2(0.2)$ \\
$J_{100}\left(10^{-2} \mathrm{~cm}^{-3} \mathrm{~s}^{-1}\right)$ & $1.2(0.23)$ & $1.3(0.41)$ & $1.3(0.81)$ \\
\hline
\end{tabular}

rates from Hyytiälä nucleation are within $5 \%$ of each other for the three sensitivity cases (Table 4 ) despite a large change in the nucleation pre-factor and a more than six-fold increase in the $J_{3}$ nucleation rate. For the $100 \mathrm{~nm}$ threshold, annualmean $\mathrm{CCN}$ formation rates due to nucleation are still within $10 \%$ of each other across simulations. While it is true that higher nucleation rates tend to result in higher $\mathrm{CCN}$ concentrations, the decreases in survival probability offset most of the increases in nucleation rates.

\subsubsection{Linking changes in condensation sink to changes in survival probability}

Although we have shown in the previous two sections that the condensation sink increases with faster nucleation rates to diminish survival probabilities, we have yet to directly link condensation sink to growth rates, coagulation sinks, and survival probability. Figure 10a is a scatterplot of simulated growth rates for one year at Hyytiälä. The red circles plotted represent the values of the TER growth rates scaled by the ratio of the condensation sinks in TER and TER5. We find that the growth rates for TER5 and "scaled TER" (which is equal to the product of the TER growth rate and the ratio of the TER and TER5 condensation sinks, i.e., $\mathrm{CS}_{\text {ter }} / \mathrm{CS}_{\text {ter5 }} \times \mathrm{GR}_{\text {ter }}$ ), are now in good agreement (within $10 \%$ of each other on average). This suggests that the growth rate decrease from the TER5 to the TER simulations can largely be explained by the increases in the condensation sink. In Fig. 10b, we find that the coagulation sink and the condensation sink are strongly correlated in our model simulations. This result has been seen in ambient measurements (Gong et al., 2010; Lehtinen et al., 2007; Dal Maso et al., 2002) and is consistent with the idea that larger particles wield the biggest influence in both the uptake of condensable vapors and the collision and combination of particles. Therefore, changes in condensation sink can be used as proxies for changes in both factors that determine survival probabilities: growth rates and coagulation scavenging frequencies.

Figure 10c and d show the relationship between survival probability (to $50 \mathrm{~nm}$, SP50) and condensation sink. In panel c, we plot survival probability as a function of condensation sink for the TER5 simulations and notice a 


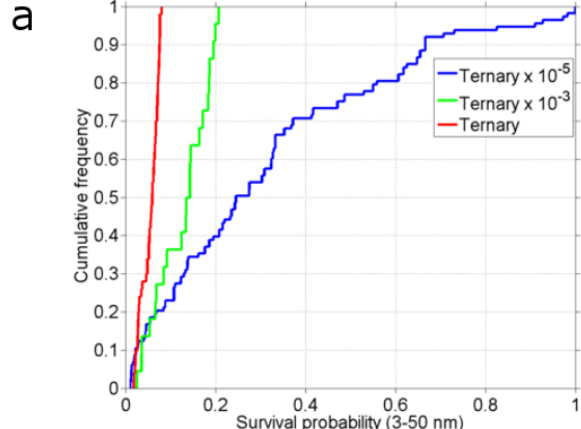

C

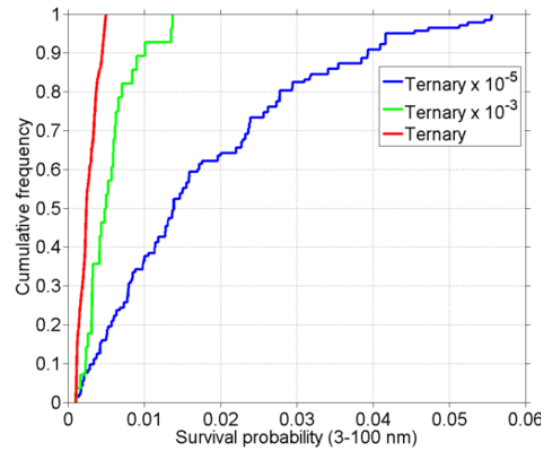

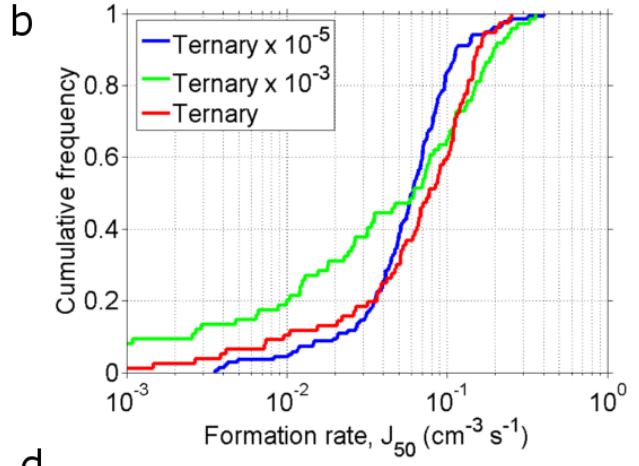

d

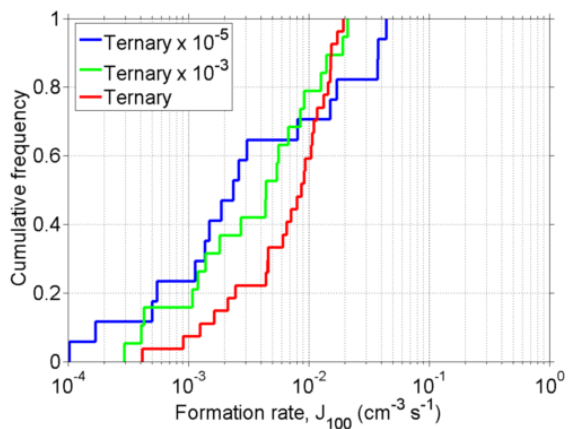

Figure 9. Cumulative distribution functions of nucleation event parameters at Hyytiälä. Red curves represent the original ternary simulation (Napari et al., 2002). Green curves represent ternary nucleation with a $10^{-3}$ tuning factor. Blue curves represent ternary nucleation with a $10^{-5}$ tuning factor. (a) Survival probability to $50 \mathrm{~nm}, \mathrm{SP}_{3-50}$ (b) $50 \mathrm{~nm}$ particle formation rate, $J_{50}\left(\mathrm{~cm}^{-3} \mathrm{~s}^{-1}\right.$ ); (c) Survival probability to $100 \mathrm{~nm}, \mathrm{SP}_{3-100}$; (d) $100 \mathrm{~nm}$ particle formation rate, $J_{100}\left(\mathrm{~cm}^{-3} \mathrm{~s}^{-1}\right)$

strong nonlinear decreasing trend, consistent with our conceptual arguments and the theory presented in Sect. 2.4 above. Since the survival probability is expected to scale with the exponential of the square of the condensation sink in the absence of large variability in the production rate of condensable vapors (Eq. 7), we attempt to fit such a function to our model output. With a tuned value of $a$, we find fairly consistent agreement $\left(R^{2}=0.9\right)$ for the negative exponential fit. Panel d is the same as c except we plot model output from the TER simulation and compare it to the same fit derived for the TER5 simulation (same equation as in panel c). We note that although there are some discrepancies, the TER5 model fit still represents the TER output well $\left(R^{2}=0.73\right)$. This supports our claim that, to the first order, the decrease in survival probability can be quantified simply from basic theory and the change in the condensation sink. This is also consistent with our claim that $\mathrm{CCN}$ concentrations do not change much with changes in nucleation theory or nucleation rate, since the same fit applies, in this specific example at least to the first order, to two nucleation schemes with vastly different nucleation rates (see Fig. 8).

There are three likely reasons for the slight discrepancy in the survival probabilities and condensation sinks between our model output and simple theory. First and foremost, if there is variability in the production rate of condensable vapors (which are not accounted for in the simplified fit), this will lead errors in the fit. There is generally little scatter in the data in Fig. 10c and d, which leads us to believe that the production rate generally does not vary randomly between event days. However, we found that in the GEOS-Chem-TOMAS model at this particular location, the production rate of condensable vapors is lower on days with lower condensation sinks (i.e., a clean aerosol background correlates with a clean gas-phase background). This correlation may be responsible for the regions of poor fit in Fig. 10d for the TER simulation. The survival probability is lower in GEOS-ChemTOMAS than in the simplified model at low condensation sinks, which may be due to lower condensable vapor production when the condensation sink is low, which would lead to slower growth rates and lower survival probabilities. However, the simple model overprediction at low condensation sinks is not evident in Fig. 10c for the TER5 simulation. This lack of overprediction maybe due to nucleation being less likely in the TER5 simulation than the TER simulation during low vapor concentrations due to the orders-of-magnitude slower nucleation rates in TER5 (Fig. 4), or alternatively it may be due to the production rate of condensable vapors being less significant as the survival probability approaches 1 (as it does for small values of condensation sink in the TER5 in Fig. 10c; this is not the case for the TER simulation). Second, condensation sink varies throughout the day (as seen in Fig. 7), but here we use the $24 \mathrm{~h}$ average in Eq. (7) to 

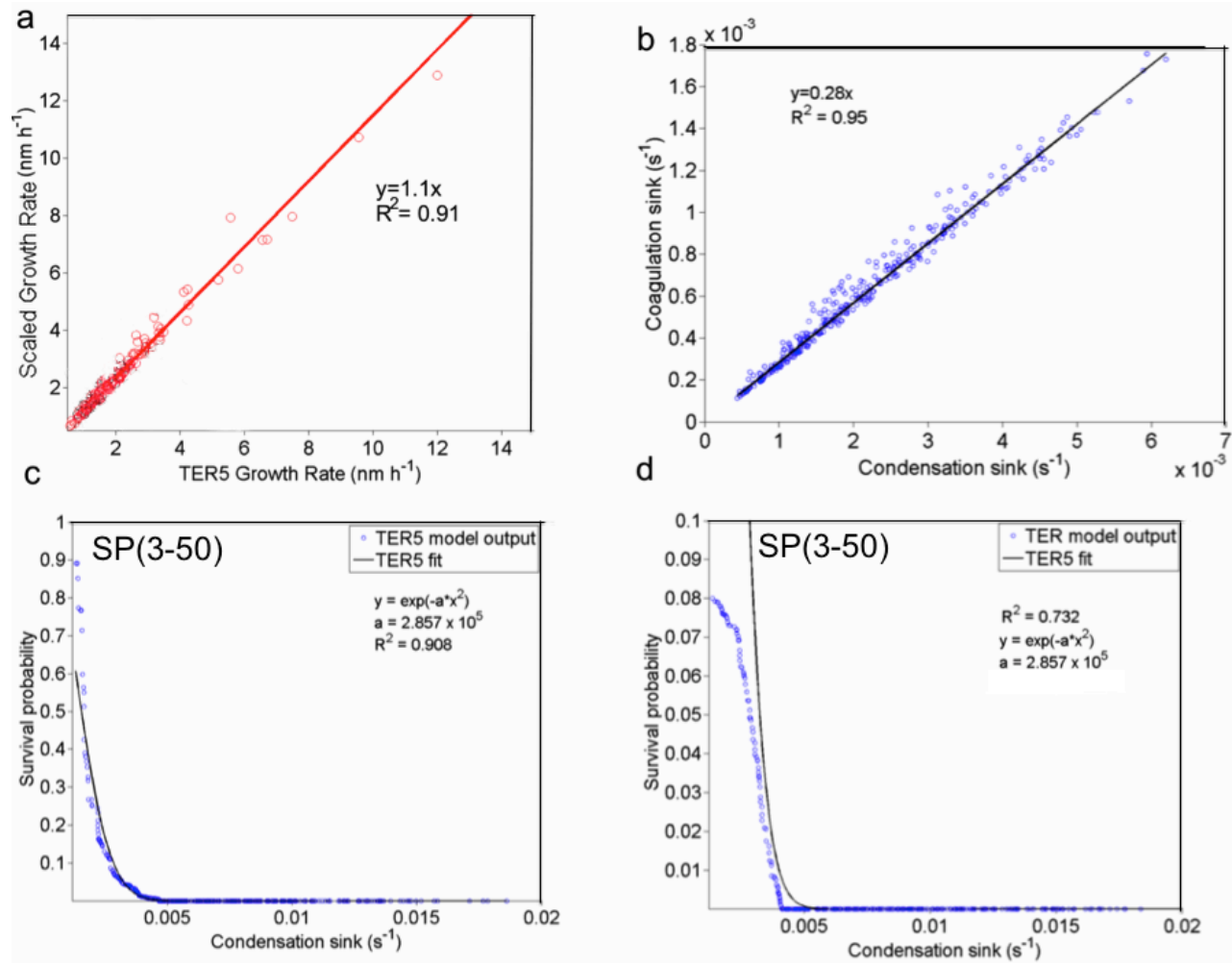

Figure 10. Explanation of the dependence of growth rates and survival probabilities on the condensation sink for one year of nucleation events at Hyytiälä. Panel (a) shows scaled TER vs. TER5 growth rates (red circles). The ternary growth rates have been scaled by the ratio of the two nucleation mechanisms' condensation sinks. Solid red line represents the line of best fit $\left(y=1.1 x, r^{2}=0.91\right)$. Panel (b) shows the correlation between coagulation sink and condensation sink. Solid blue line is best fit $\left(y=0.28 x, r^{2}=0.95\right)$. Panel (c) shows the plot of survival probability (to $50 \mathrm{~nm}$ ) vs. condensation sink for the TER5 simulations (blue circles). Solid black line represents a model fit to the TER5 data of the form $y=\exp \left(-a \cdot x^{2}\right)$ as described in the text. Value of a is given in the figure. Panel (d) is the same as (c), except that the TER model output (blue circles) is compared to the same TER5 fit from panel (c) (same equation and coefficients).

predict changes in survival probability. Since the condensation sink is larger shortly after a nucleation burst, our model points (GEOS-Chem-TOMAS) may be shifted slightly to the right in Fig. 10d, leading to better agreement. Third, the correlation between CoagS and CS assumed by our theory is mostly valid only for the kinetic regime and may not be applicable to the transition regime $(\sim 100 \mathrm{~nm})$. If the CoagS is actually smaller than predicted by our simple theory, the model output survival probability may agree better. Despite these shortcomings, the simple relationship between CS and SP is broadly confirmed within the GEOS-Chem-TOMAS framework. However, we have yet to confirm if this relationship holds for field data where it is possible that the production rate of condensable vapors varies more strongly and independently from the condensation sink.

\section{Conclusions}

Using the GEOS-Chem-TOMAS global aerosol microphysics model, we performed a series of 16 simulations with 8 differing nucleation mechanisms (or pre-factors) and 2
SOA budgets in order to test the sensitivity of $\mathrm{CCN}$ to nucleation and growth. In addition to determining the sensitivity, we analyzed one year of modeled nucleation events at Hyytiälä in order to explain and quantify the reasons for the apparently modest sensitivity of $\mathrm{CCN}$ to nucleation. We calculated modeled growth rates, condensation sinks, coagulation sinks, survival probabilities, and $\mathrm{CCN}$ formation rates and used these properties to explain the microphysical feedbacks that lead to a buffered response in CCN due to increased nucleation rates. Global modeling results showed that $N_{10}$ is generally more sensitive to nucleation than $\mathrm{CCN}(0.2 \%)$ consistent with the fact that nuclei are lost by coagulation during growth but some primary particles are emitted already at or near CCN sizes. The global, boundary layer averaged increase in $N_{10}$ due to adding nucleation schemes to a simulation with no nucleation varied from $23 \%$ in the BHN scheme to $190 \%$ in the TER5 scheme. Spatially, the activation simulation (ACT2) predicted large increases in $N_{10}$ in most boundary layer locations, including over the oceans, while other cases (binary (BHN), ternary with the $10^{-5}$ pre-factor (TER5)) predicted less dramatic increases 
limited mostly to the continents. In particular, the lack of sufficient boundary layer nucleation in the BHN simulation caused BHN to be the least sensitive in $N_{10}$ to nucleation.

Enhancements of $\mathrm{CCN}(0.2 \%)$ above the NONUC simulation were less sensitive to the choice of nucleation parameterization, ranging from $49-78 \%$ average increases in the boundary layer. This $29 \%$ difference in $\mathrm{CCN}(0.2 \%)$ is nonnegligible, but not especially large considering the large uncertainties (factors of 2) in other aerosol indirect effect predictions. Because our results showed that binary nucleation alone increases $\mathrm{CCN}(0.2 \%)$ almost as much as ternary or activation nucleation, this implies that free tropospheric nucleation contributes a significant amount of the nucleationderived CCN, similar to what was found in (Merikanto et al., 2009).

We explored the details of the aerosol physics in the global model to explain further the weak sensitivity of CCN to the specific nucleation mechanism and nucleation rate. Given a fixed budget of condensable aerosol mass (sulfate and SOA), any increase in $\mathrm{CCN}$ concentrations due to nucleation and growth imply that the CCN or accumulation mode shifts to smaller sizes. Therefore, overall surface area is higher, leading to two negative feedbacks on subsequent nucleation and growth events. First, higher surface area means higher condensation sink and slower growth rates. Second, higher condensation sink correlates with faster coagulation scavenging. The net result of these two feedbacks is that it takes nucleated particles longer to grow to $\mathrm{CCN}$ sizes, during which time they are subject to more intense coagulation scavenging. Therefore, with faster nucleation mechanisms, nuclei grow more slowly and are exposed to higher coagulation loss frequencies for longer periods of time, limiting their survival to $\mathrm{CCN}$ sizes, and reducing the impact that nucleation rates would otherwise have on $\mathrm{CCN}$ concentrations. Both feedbacks lower survival probabilities, and the net effect is often dramatic. We showed that the full three-dimensional model's predicted decrease in survival probability with higher nucleation rates quantitatively matched what would be expected using a simple theory that accounts for these two feedbacks.

We use one year of model output for Hyytiälä as an example of these feedback processes at work. We analyzed one year of size distribution output for three ternary simulations, TER5, TER3, and TER with different pre-factors tuning their nucleation rates. These three scenarios represented incremental changes in the nucleation rates that allowed us to observe effects of increased nucleation on other quantities that effect growth to CCN sizes. Specifically, the growth rates in the faster nucleation cases (TER, TER3) were diminished by $50 \%$ on average because of an increased sink of condensable vapors. Particle survival probability was decreased due to the decrease in growth rate and increase in coagulation, evening out the $\mathrm{CCN}$ formation rates across the three simulations. The faster nucleation mechanisms (TER, TER3) did have higher CCN formation rates, but the annualaverage $\mathrm{CCN}$ formation rates attributable to nucleation were within $10 \%$ of each other at both 50 and $100 \mathrm{~nm} \mathrm{CCN} \mathrm{size}$ thresholds.

We explored the relationship between $\mathrm{CCN}$ concentrations and nucleation rates, $J_{1}$, on a global scale for all of the nucleation scenarios plus an additional series of simulations that included an extra $100 \mathrm{Tg} \mathrm{yr}^{-1}$ of SOA available for condensation. The boundary layer $\operatorname{CCN}(0.2 \%)$ without the extra SOA varied only by 40 particles $\mathrm{cm}^{-3}(29 \%)$ between all of the nucleation simulations - a nucleation rate range of about 4 orders of magnitude. The sensitivity range drops to $\sim 12 \%$ when we eliminate nucleation parameterizations (BHN and TER) known to exhibit serious biases compared to observed nucleation rates. Despite this, even the slowest nucleation simulation (BHN) increased $\mathrm{CCN}$ by about $50 \%$ over the NONUC control simulation. This suggests that the presence of any nucleation theory in the model has a larger effect than the differences resulting from choice of nucleation parameterization. There are interesting exceptions, however, such as the BHN and ION simulations, which have nearly identical global-average nucleation rates but noticeably different $\mathrm{CCN}$ formation, implying that survival probability is different depending on when and where nucleation occurs. With extra $\mathrm{SOA}, \mathrm{CCN}(0.2 \%)$ are much more sensitive to nucleation, indicating that particles that normally would not reach activation sizes are indeed reaching those sizes when additional SOA is available to enhance growth. We also find that $\mathrm{CCN}(1.0 \%)$ are more sensitive to nucleation due to the capability of smaller particles $(30-60 \mathrm{~nm}$, depending on composition) to be activated and the greater ease with which nuclei can reach these moderate sizes.

Our model results indicate that nucleation makes a significant contribution to aerosol number concentrations, including $\mathrm{CCN}$, but that boundary layer $\mathrm{CCN}$ are not very sensitive to the choice of nucleation parameterization once obvious outliers (BHN and TER) are excluded. Comparing the results of $\mathrm{BHN}$ and $\mathrm{ACT}$ simulations, it is clear that much of the contribution to boundary layer $\mathrm{CCN}$ results from nucleation in the free troposphere, consistent with previous work (Merikanto et al., 2009). The overall modest impact is due to a dampening effect on $\mathrm{CCN}$ from an increased aerosol Fuchs surface area, subsequent loss of condensable vapors, and the accompanying increase in coagulation scavenging. While sensitivity studies such as the one we have presented here are useful, they are limited by the nonlinear nature of aerosol model processes. Future work must be aimed at directly determining the nucleation contribution to $\mathrm{CCN}$ through other methods.

Acknowledgements. This research was pursued with funds from the US Environmental Protection Agency under EPA Agreement RD-83337401 and STAR Grant RD-83503501. We acknowledge the Atlantic Computational Excellence Network (ACEnet) for providing the computational resources required for this work.

Edited by: V.-M. Kerminen 


\section{References}

Adams, P. J. and Seinfeld, J. H.: Predicting global aerosol size distributions in general circulation models, J. Geophys. Res.-Atmos., 107, 4370, doi:10.1029/2001jd001010, 2002.

Adams, P. J. and Seinfeld, J. H.: Disproportionate impact of particulate emissions on global cloud condensation nuclei concentrations, Geophys. Res. Lett., 30, 1239, doi:10.1029/2002g1016303, 2003.

Albrecht, B.: Aerosols, Cloud Microphysics, and Fractional Cloudiness, Science, 245, 1227-1230, doi:10.1126/science.245.4923.1227, 1989.

Almeida, J., Schobesberger, S., Kürten, A., Ortega, I. K., Kupiainen-Määttä, O., Praplan, A. P., Adamov, A., Amorim, A., Bianchi, F., Breitenlechner, M., David, A., Dommen, J., Donahue, N. M., Downard, A., Dunne, E., Duplissy, J., Ehrhart, S., Flagan, R. C., Franchin, A., Guida, R., Hakala, J., Hansel, A., Heinritzi, M., Henschel, H., Jokinen, T., Junninen, H., Kajos, M., Kangasluoma, J., Keskinen, H., Kupc, A., Kurtén, T., Kvashin, A. N., Laaksonen, A., Lehtipalo, K., Leiminger, M., Leppä, J., Loukonen, V., Makhmutov, V., Mathot, S., McGrath, M. J., Nieminen, T., Olenius, T., Onnela, A., Petäjä, T., Riccobono, F., Riipinen, I., Rissanen, M., Rondo, L., Ruuskanen, T., Santos, F. D., Sarnela, N., Schallhart, S., Schnitzhofer, R., Seinfeld, J. H., Simon, M., Sipilä, M., Stozhkov, Y., Stratmann, F., Tomé, A., Tröstl, J., Tsagkogeorgas, G., Vaattovaara, P., Viisanen, Y., Virtanen, A., Vrtala, A., Wagner, P. E., Weingartner, E., Wex, H., Williamson, C., Wimmer, D., Ye, P., Yli-Juuti, T., Carslaw, K. S., Kulmala, M., Curtius, J., Baltensperger, U., Worsnop, D. R., Vehkamäki, H., and Kirkby, J.: Molecular understanding of sulphuric acid-amine particle nucleation in the atmosphere, Nature, 502, 359-63, doi:10.1038/nature12663, 2013.

Auvray, M. and Bey, I.: Long-range transport to Europe: Seasonal variations and implications for the European ozone budget, J. Geophys. Res., 110, D11303, doi:10.1029/2004JD005503, 2005.

Ball, S. M., Hanson, D. R., Eisele, F. L., and McMurry, P. H.: Laboratory studies of particle nucleation: Initial results for $\mathrm{H}_{2} \mathrm{SO}_{4}$, $\mathrm{H}_{2} \mathrm{O}$, and $\mathrm{NH}_{3}$ vapors, J. Geophys. Res., 104, 23709-23718, doi:10.1029/1999JD900411, 1999.

Berndt, T., Böge, O., Stratmann, F., Heintzenberg, J., and Kulmala, M.: Rapid Formation of Sulfuric Acid Particles at Near-Atmospheric Conditions, Science, 307, 698-700, doi:10.1126/science.1104054, 2005.

Bey, I., Jacob, D. J., Yantosca, R. M., Logan, J. A., Field, B. D., Fiore, A. M., Li, Q. B., Liu, H. G. Y., Mickley, L. J., and Schultz, M. G.: Global modeling of tropospheric chemistry with assimilated meteorology: Model description and evaluation, J. Geophys. Res., 106, 23073-23095, 2001.

Bzdek, B. R., Ridge, D. P., and Johnston, M. V.: SizeDependent Reactions of Ammonium Bisulfate Clusters with Dimethylamine, J. Phys. Chem. A, 114, 11638-11644, doi:10.1021/jp106363m, 2010.

Chen, M., Titcombe, M., Jiang, J., Jen, C., Kuang, C., Fischer, M. L., Eisele, F. L., Siepmann, J. I., Hanson, D. R., Zhao, J., and McMurry, P. H.: Acid-base chemical reaction model for nucleation rates in the polluted atmospheric boundary layer., P. Natl. Acad. Sci. USA, 109, 18713-18718, doi:10.1073/pnas.1210285109, 2012.

Dal Maso, M., Kulmala, M., Lehtinen, K. E. J., Mäkelä, J. M., Aalto, P., and O'Dowd, C. D.: Condensation and coagulation sinks and formation of nucleation mode particles in coastal and boreal forest boundary layers, J. Geophys. Res., 107, 2-1-2-10, doi:10.1029/2001JD001053, 2002.

Dal Maso, M., Kulmala, M., Riipinen, I., Wagner, R., Hussein, T., Aalto, P. P., and Lehtinen, K. E. J.: Formation and growth of fresh atmospheric aerosols: eight years of aerosol size distribution data from SMEAR II, Hyytiala, Finland, Boreal Environ. Res., 10, 323-336, 2005.

D’Andrea, S. D., Häkkinen, S. A. K., Westervelt, D. M., Kuang, C., Levin, E. J. T., Kanawade, V. P., Leaitch, W. R., Spracklen, D. V., Riipinen, I., and Pierce, J. R.: Understanding global secondary organic aerosol amount and size-resolved condensational behavior, Atmos. Chem. Phys., 13, 11519-11534, doi:10.5194/acp-1311519-2013, 2013.

Donahue, N. M., Robinson, A. L., Stanier, C. O., and Pandis, S. N.: Coupled Partitioning, Dilution, and Chemical Aging of Semivolatile Organics, Environ. Sci. Technol., 40, 2635-2643, doi:10.1021/es052297c, 2006.

Donahue, N. M., Trump, E. R., Pierce, J. R., and Riipinen, I.: Theoretical constraints on pure vapor-pressure driven condensation of organics to ultrafine particles, Geophys. Res. Lett., 38, L16801, doi:10.1029/2011GL048115, 2011.

Doyle, G. J.: Self-Nucleation in the Sulfuric Acid-Water System, J. Chem. Phys., 35, 795-799, doi:10.1063/1.1701218, 1961.

Erupe, M. E., Benson, D. R., Li, J., Young, L.-H., Verheggen, B., Al-Refai, M., Tahboub, O., Cunningham, V., Frimpong, F., Viggiano, A. A., and Lee, S.-H.: Correlation of aerosol nucleation rate with sulfuric acid and ammonia in Kent, Ohio: An atmospheric observation, J. Geophys. Res., 115, D23216, doi:10.1029/2010JD013942, 2010.

Facchini, M. C., Mircea, M., Fuzzi, S., and Charlson, R. J.: Cloud albedo enhancement by surface-active organic solutes in growing droplets, Nature, 401, 257-259, doi:10.1038/45758, 1999.

Gagné, S., Nieminen, T., Kurtén, T., Manninen, H. E., Petäjä, T., Laakso, L., Kerminen, V.-M., Boy, M., and Kulmala, M.: Factors influencing the contribution of ion-induced nucleation in a boreal forest, Finland, Atmos. Chem. Phys., 10, 3743-3757, doi:10.5194/acp-10-3743-2010, 2010.

Goldstein, A. H. and Gallaby, I. E.: Known and unexplored organic constituents in the earth's atmosphre, Environ. Sci. Technol., 41, 1514-1521, doi:10.1021/es072476p, 2007.

Gong, Y., Hu, M., Cheng, Y., Su, H., Yue, D., Liu, F., Wiedensohler, A., Wang, Z., Kalesse, H., and Liu, S.: Competition of coagulation sink and source rate: New particle formation in the Pearl River Delta of China, Atmos. Environ., 44, 3278-3285, doi:10.1016/j.atmosenv.2010.05.049, 2010.

Guenther, A., Karl, T., Harley, P., Wiedinmyer, C., Palmer, P. I., and Geron, C.: Estimates of global terrestrial isoprene emissions using MEGAN (Model of Emissions of Gases and Aerosols from Nature), Atmos. Chem. Phys., 6, 3181-3210, doi:10.5194/acp-63181-2006, 2006.

Heald, C. L., Coe, H., Jimenez, J. L., Weber, R. J., Bahreini, R., Middlebrook, A. M., Russell, L. M., Jolleys, M., Fu, T.-M., Allan, J. D., Bower, K. N., Capes, G., Crosier, J., Morgan, W. T., Robinson, N. H., Williams, P. I., Cubison, M. J., DeCarlo, P. F., and Dunlea, E. J.: Exploring the vertical profile of atmospheric organic aerosol: comparing 17 aircraft field campaigns with a global model, Atmos. Chem. Phys., 11, 12673-12696, doi:10.5194/acp-11-12673-2011, 2011. 
Jung, J., Adams, P. J., and Pandis, S. N.: Simulating the size distribution and chemical composition of ultrafine particles during nucleation events, Atmos. Environ., 40, 2248-2259, doi:10.1016/j.atmosenv.2005.09.082, 2006.

Jung, J., Fountoukis, C., Adams, P. J., and Pandis, S. N.: Simulation of in situ ultrafine particle formation in the eastern United States using PMCAMx-UF, J. Geophys. Res., 115, D03203, doi:10.1029/2009JD012313, 2010.

Kerminen, V.-M.: Direct observational evidence linking atmospheric aerosol formation and cloud droplet activation, Geophys. Res. Lett., 32, L14803, doi:10.1029/2005GL023130, 2005.

Kerminen, V.-M. and Kulmala, M.: Analytical formulae connecting the "real" and the "apparent" nucleation rate and the nuclei number concentration for atmospheric nucleation events, J. Aerosol Sci., 33, 609-622, doi:10.1016/S0021-8502(01)00194-X, 2002.

Kirkby, J., Curtius, J., Almeida, J., Dunne, E., Duplissy, J., Ehrhart, S., Franchin, A., Gagne, S., Ickes, L., Kurten, A., Kupc, A., Metzger, A., Riccobono, F., Rondo, L., Schobesberger, S., Tsagkogeorgas, G., Wimmer, D., Amorim, A., Bianchi, F., Breitenlechner, M., David, A., Dommen, J., Downard, A., Ehn, M., Flagan, R. C., Haider, S., Hansel, A., Hauser, D., Jud, W., Junninen, H., Kreissl, F., Kvashin, A., Laaksonen, A., Lehtipalo, K., Lima, J., Lovejoy, E. R., Makhmutov, V., Mathot, S., Mikkila, J., Minginette, P., Mogo, S., Nieminen, T., Onnela, A., Pereira, P., Petaja, T., Schnitzhofer, R., Seinfeld, J. H., Sipila, M., Stozhkov, Y., Stratmann, F., Tome, A., Vanhanen, J., Viisanen, Y., Vrtala, A., Wagner, P. E., Walther, H., Weingartner, E., Wex, H., Winkler, P. M., Carslaw, K. S., Worsnop, D. R., Baltensperger, U., and Kulmala, M.: Role of sulphuric acid, ammonia and galactic cosmic rays in atmospheric aerosol nucleation, Nature, 476, 429-433, doi:10.1038/nature10343, 2011.

Kuang, C., McMurry, P. H., McCormick, A. V., and Eisele, F. L.: Dependence of nucleation rates on sulfuric acid vapor concentration in diverse atmospheric locations, J. Geophys. Res., 113, D10209, doi:10.1029/2007JD009253, 2008.

Kuang, C., McMurry, P. H., and McCormick, A. V.: Determination of cloud condensation nuclei production from measured new particle formation events, Geophys. Res. Lett., 36, L09822, doi:10.1029/2009GL037584, 2009.

Kulmala, M. and Laaksonen, A.: Binary Nucleation of Water Sulfuric-Acid System - Comparison of Classical-Theories with Different $\mathrm{H}_{2} \mathrm{SO}_{4}$ Saturation Vapor-Pressures, J. Chem. Phys., 93, 696-701, 1990.

Kulmala, M., Pirjola, L., and Makela, J. M.: Stable sulphate clusters as a source of new atmospheric particles, Nature, 404, 66-69, doi:10.1038/35003550, 2000.

Kulmala, M., Laakso, L., Lehtinen, K. E. J., Riipinen, I., Dal Maso, M., Anttila, T., Kerminen, V.-M., Hõrrak, U., Vana, M., and Tammet, H.: Initial steps of aerosol growth, Atmos. Chem. Phys., 4, 2553-2560, doi:10.5194/acp-4-2553-2004, 2004.

Kulmala, M., Lehtinen, K. E. J., and Laaksonen, A.: Cluster activation theory as an explanation of the linear dependence between formation rate of $3 \mathrm{~nm}$ particles and sulphuric acid concentration, Atmos. Chem. Phys., 6, 787-793, doi:10.5194/acp-6-787-2006, 2006.

Kulmala, M., Kontkanen, J., Junninen, H., Lehtipalo, K., Manninen, H. E., Nieminen, T., Petäjä, T., Sipilä, M., Schobesberger, S., Rantala, P., Franchin, A., Jokinen, T., Järvinen, E., Äijälä, M., Kangasluoma, J., Hakala, J., Aalto, P. P., Paasonen, P., Mikkilä,
J., Vanhanen, J., Aalto, J., Hakola, H., Makkonen, U., Ruuskanen, T., Mauldin, R. L., Duplissy, J., Vehkamäki, H., Bäck, J., Kortelainen, A., Riipinen, I., Kurtén, T., Johnston, M. V., Smith, J. N., Ehn, M., Mentel, T. F., Lehtinen, K. E. J., Laaksonen, A., Kerminen, V.-M., and Worsnop, D. R.: Direct observations of atmospheric aerosol nucleation., Science, 339, 943-946, doi:10.1126/science.1227385, 2013.

Kurtén, T., Loukonen, V., Vehkamäki, H., and Kulmala, M.: Amines are likely to enhance neutral and ion-induced sulfuric acid-water nucleation in the atmosphere more effectively than ammonia, Atmos. Chem. Phys., 8, 4095-4103, doi:10.5194/acp-8-4095-2008, 2008.

Laakso, L., Gagné, S., Petäjä, T., Hirsikko, A., Aalto, P. P., Kulmala, M., and Kerminen, V.-M.: Detecting charging state of ultrafine particles: instrumental development and ambient measurements, Atmos. Chem. Phys., 7, 1333-1345, doi:10.5194/acp-71333-2007, 2007.

Lee, L. A., Pringle, K. J., Reddington, C. L., Mann, G. W., Stier, P., Spracklen, D. V., Pierce, J. R., and Carslaw, K. S.: The magnitude and causes of uncertainty in global model simulations of cloud condensation nuclei, Atmos. Chem. Phys., 13, 8879-8914, doi:10.5194/acp-13-8879-2013, 2013.

Lee, Y. H., Chen, K., and Adams, P. J.: Development of a global model of mineral dust aerosol microphysics, Atmos. Chem. Phys., 9, 2441-2458, doi:10.5194/acp-9-2441-2009, 2009.

Lee, Y. H., Pierce, J. R., and Adams, P. J.: Representation of nucleation mode microphysics in a global aerosol model with sectional microphysics, Geosci. Model Dev., 6, 1221-1232, doi:10.5194/gmd-6-1221-2013, 2013.

Lehtinen, K. E. J., Dal Maso, M., Kulmala, M., and Kerminen, V.-M.: Estimating nucleation rates from apparent particle formation rates and vice versa: Revised formulation of the Kerminen-Kulmala equation, J. Aerosol Sci., 38, 988-994, doi:10.1016/j.jaerosci.2007.06.009, 2007.

Mäkelä, J. M., Aalto, P., Jokinen, V., Pohja, T., Nissinen, A., Palmroth, S., Markkanen, T., Seitsonen, K., Lihavainen, H., and Kulmala, M.: Observations of ultrafine aerosol particle formation and growth in boreal forest, Geophys. Res. Lett., 24, 1219-1222, doi:199710.1029/97GL00920, 1997.

Makkonen, R., Asmi, A., Korhonen, H., Kokkola, H., Järvenoja, S., Räisänen, P., Lehtinen, K. E. J., Laaksonen, A., Kerminen, V.M., Järvinen, H., Lohmann, U., Bennartz, R., Feichter, J., and Kulmala, M.: Sensitivity of aerosol concentrations and cloud properties to nucleation and secondary organic distribution in ECHAM5-HAM global circulation model, Atmos. Chem. Phys., 9, 1747-1766, doi:10.5194/acp-9-1747-2009, 2009.

Makkonen, R., Asmi, A., Kerminen, V.-M., Boy, M., Arneth, A., Guenther, A., and Kulmala, M.: BVOC-aerosol-climate interactions in the global aerosol-climate model ECHAM5.5-HAM2, Atmos. Chem. Phys., 12, 10077-10096, doi:10.5194/acp-1210077-2012, 2012.

Manninen, H. E., Nieminen, T., Riipinen, I., Yli-Juuti, T., Gagné, S., Asmi, E., Aalto, P. P., Petäjä, T., Kerminen, V.-M., and Kulmala, M.: Charged and total particle formation and growth rates during EUCAARI 2007 campaign in Hyytiälä, Atmos. Chem. Phys., 9, 4077-4089, doi:10.5194/acp-9-4077-2009, 2009.

McMurry, P. H., Fink, M., Sakurai, H., Stolzenburg, M. R., Mauldin, R. L., Smith, J., Eisele, F., Moore, K., Sjostedt, S., Tanner, D., Huey, L. G., Nowak, J. B., Edgerton, E., 
and Voisin, D.: A criterion for new particle formation in the sulfur-rich Atlanta atmosphere, J. Geophys. Res., 110, D22S02, doi:10.1029/2005JD005901, 2005.

Merikanto, J., Napari, I., Vehkamäki, H., Anttila, T., and Kulmala, M.: New parameterization of sulfuric acid-ammonia-water ternary nucleation rates at tropospheric conditions, J. Geophys. Res., 112, D15207, doi:10.1029/2006JD007977, 2007.

Merikanto, J., Spracklen, D. V., Mann, G. W., Pickering, S. J., and Carslaw, K. S.: Impact of nucleation on global CCN, Atmos. Chem. Phys., 9, 8601-8616, doi:10.5194/acp-9-8601-2009, 2009.

Metzger, A., Verheggen, B., Dommen, J., Duplissy, J., Prevot, A. S. H., Weingartner, E., Riipinen, I., Kulmala, M., Spracklen, D. V., Carslaw, K. S., and Baltensperger, U.: Evidence for the role of organics in aerosol particle formation under atmospheric conditions., P. Natl. Acad. Sci. USA, 107, 6646-6651, doi:10.1073/pnas.0911330107, 2010.

Napari, I., Kulmala, M., and Vehkamaki, H.: Ternary nucleation of inorganic acids, ammonia, and water, J. Chem. Phys., 117, 8418 8425, doi:10.1063/1.1511722, 2002.

Noppel, M., Vehkamäki, H., and Kulmala, M.: An improved model for hydrate formation in sulfuric acid-water nucleation, J. Chem. Phys., 116, 218-228, doi:10.1063/1.1423333, 2002.

Olivier, J. G. J., Bouwman, A. F., Van der Maas, C. W. M., Berdowski, J. J. M., Veldt, C., Bloos, J. P. J., Visschedijk, A. J. H., Zandveld, P. Y. J., and Haverlag, J. L.: Description of EDGAR Version 2.0: A set of global emission inventories of greenhouse gases and ozone depleting substances for all anthropogenic and most natural sources on a per country basis and on $1 \times 1$ grid, National Institute of Public Health and the Environment (RIVM) report no. 771060 002, Netherlands Organization for Applied Scientific Research (TNO), 1996.

Paasonen, P., Nieminen, T., Asmi, E., Manninen, H. E., Petäjä, T., Plass-Dülmer, C., Flentje, H., Birmili, W., Wiedensohler, A., Hõrrak, U., Metzger, A., Hamed, A., Laaksonen, A., Facchini, M. C., Kerminen, V.-M., and Kulmala, M.: On the roles of sulphuric acid and low-volatility organic vapours in the initial steps of atmospheric new particle formation, Atmos. Chem. Phys., 10, 11223-11242, doi:10.5194/acp-10-11223-2010, 2010.

Pandis, S. N., Baltensperger, U., Wolfenbarger, J. K., and Seinfeld, J. H.: Inversion of aerosol data from the epiphaniometer, J. Aerosol Sci., 22, 417-428, doi:10.1016/0021-8502(91)90002-Y, 1991.

Pierce, J. R. and Adams, P. J.: Global evaluation of CCN formation by direct emission of sea salt and growth of ultrafine sea salt, J. Geophys. Res., 111, D06203, doi:10.1029/2005JD006186, 2006.

Pierce, J. R. and Adams, P. J.: Efficiency of cloud condensation nuclei formation from ultrafine particles, Atmos. Chem. Phys., 7, 1367-1379, doi:10.5194/acp-7-1367-2007, 2007.

Pierce, J. R. and Adams, P. J.: A Computationally Efficient Aerosol Nucleation/ Condensation Method: PseudoSteady-State Sulfuric Acid, Aerosol Sci. Tech., 43, 216-226, doi:10.1080/02786820802587896, 2009a.

Pierce, J. R. and Adams, P. J.: Uncertainty in global CCN concentrations from uncertain aerosol nucleation and primary emission rates, Atmos. Chem. Phys., 9, 1339-1356, doi:10.5194/acp-91339-2009, 2009b.
Pierce, J. R., Chen, K., and Adams, P. J.: Contribution of primary carbonaceous aerosol to cloud condensation nuclei: processes and uncertainties evaluated with a global aerosol microphysics model, Atmos. Chem. Phys., 7, 5447-5466, doi:10.5194/acp-75447-2007, 2007.

Pierce, J. R., Riipinen, I., Kulmala, M., Ehn, M., Petäjä, T., Junninen, H., Worsnop, D. R., and Donahue, N. M.: Quantification of the volatility of secondary organic compounds in ultrafine particles during nucleation events, Atmos. Chem. Phys., 11, 90199036, doi:10.5194/acp-11-9019-2011, 2011.

Pierce, J. R., Leaitch, W. R., Liggio, J., Westervelt, D. M., Wainwright, C. D., Abbatt, J. P. D., Ahlm, L., Al-Basheer, W., Cziczo, D. J., Hayden, K. L., Lee, A. K. Y., Li, S.-M., Russell, L. M., Sjostedt, S. J., Strawbridge, K. B., Travis, M., Vlasenko, A., Wentzell, J. J. B., Wiebe, H. A., Wong, J. P. S., and Macdonald, A. M.: Nucleation and condensational growth to $\mathrm{CCN}$ sizes during a sustained pristine biogenic SOA event in a forested mountain valley, Atmos. Chem. Phys., 12, 3147-3163, doi:10.5194/acp-12-3147-2012, 2012.

Raymond, T. M. and Pandis, S. N.: Formation of cloud droplets by multicomponent organic particles, J. Geophys. Res., 108, 4469, doi:10.1029/2003JD003503, 2003.

Reddington, C. L., Carslaw, K. S., Spracklen, D. V., Frontoso, M. G., Collins, L., Merikanto, J., Minikin, A., Hamburger, T., Coe, H., Kulmala, M., Aalto, P., Flentje, H., Plass-Dülmer, C., Birmili, W., Wiedensohler, A., Wehner, B., Tuch, T., Sonntag, A., O’Dowd, C. D., Jennings, S. G., Dupuy, R., Baltensperger, U., Weingartner, E., Hansson, H.-C., Tunved, P., Laj, P., Sellegri, K., Boulon, J., Putaud, J.-P., Gruening, C., Swietlicki, E., Roldin, P., Henzing, J. S., Moerman, M., Mihalopoulos, N., Kouvarakis, G., Ždímal, V., Zíková, N., Marinoni, A., Bonasoni, P., and Duchi, R.: Primary versus secondary contributions to particle number concentrations in the European boundary layer, Atmos. Chem. Phys., 11, 12007-12036, doi:10.5194/acp-11-12007-2011, 2011.

Riipinen, I., Pierce, J. R., Yli-Juuti, T., Nieminen, T., Häkkinen, S., Ehn, M., Junninen, H., Lehtipalo, K., Petäjä, T., Slowik, J., Chang, R., Shantz, N. C., Abbatt, J., Leaitch, W. R., Kerminen, V.-M., Worsnop, D. R., Pandis, S. N., Donahue, N. M., and Kulmala, M.: Organic condensation: a vital link connecting aerosol formation to cloud condensation nuclei (CCN) concentrations, Atmos. Chem. Phys., 11, 3865-3878, doi:10.5194/acp-11-38652011, 2011.

Seinfeld, J. H. and Pandis, S. N.: Atmospheric Chemistry and Physics, 1st Edn., John Wiley and Sons, New York, 2006.

Sihto, S.-L., Kulmala, M., Kerminen, V.-M., Dal Maso, M., Petäjä, T., Riipinen, I., Korhonen, H., Arnold, F., Janson, R., Boy, M., Laaksonen, A., and Lehtinen, K. E. J.: Atmospheric sulphuric acid and aerosol formation: implications from atmospheric measurements for nucleation and early growth mechanisms, Atmos. Chem. Phys., 6, 4079-4091, doi:10.5194/acp-6-4079-2006, 2006.

Sipilä, M., Berndt, T., Petäjä, T., Brus, D., Vanhanen, J., Stratmann, F., Patokoski, J., Mauldin, R. L., Hyvärinen, A.P., Lihavainen, H., and Kulmala, M.: The role of sulfuric acid in atmospheric nucleation., Science, 327, 1243-1246, doi:10.1126/science.1180315, 2010.

Spracklen, D. V., Carslaw, K. S., Kulmala, M., Kerminen, V.-M., Sihto, S.-L., Riipinen, I., Merikanto, J., Mann, G. W., Chipperfield, M. P., Wiedensohler, A., Birmili, W., and Lihavainen, 
H.: Contribution of particle formation to global cloud condensation nuclei concentrations, Geophys. Res. Lett., 35, L06808, doi:10.1029/2007GL033038, 2008.

Spracklen, D. V., Carslaw, K. S., Merikanto, J., Mann, G. W., Reddington, C. L., Pickering, S., Ogren, J. A., Andrews, E., Baltensperger, U., Weingartner, E., Boy, M., Kulmala, M., Laakso, L., Lihavainen, H., Kivekäs, N., Komppula, M., Mihalopoulos, N., Kouvarakis, G., Jennings, S. G., O’Dowd, C., Birmili, W., Wiedensohler, A., Weller, R., Gras, J., Laj, P., Sellegri, K., Bonn, B., Krejci, R., Laaksonen, A., Hamed, A., Minikin, A., Harrison, R. M., Talbot, R., and Sun, J.: Explaining global surface aerosol number concentrations in terms of primary emissions and particle formation, Atmos. Chem. Phys., 10, 4775-4793, doi:10.5194/acp-10-4775-2010, 2010.

Spracklen, D. V., Jimenez, J. L., Carslaw, K. S., Worsnop, D. R., Evans, M. J., Mann, G. W., Zhang, Q., Canagaratna, M. R., Allan, J., Coe, H., McFiggans, G., Rap, A., and Forster, P.: Aerosol mass spectrometer constraint on the global secondary organic aerosol budget, Atmos. Chem. Phys., 11, 12109-12136, doi:10.5194/acp-11-12109-2011, 2011.

Streets, D. G., Bond, T. C., Carmichael, G. R., Fernandes, S. D., Fu, Q., Klimont, Z., Nelson, S. M., Tsai, N. Y., Wang, M. Q., Woo, J.-H., and Yarber, K. F.: An inventory of gaseous and primary aerosol emissions in Asia in the year 2000, J. Geophys. Res, 108, 8809, doi:10.1029/2002JD003093, 2003.

Trivitayanurak, W., Adams, P. J., Spracklen, D. V., and Carslaw, K. S.: Tropospheric aerosol microphysics simulation with assimilated meteorology: model description and intermodel comparison, Atmos. Chem. Phys., 8, 3149-3168, doi:10.5194/acp-83149-2008, 2008.

Twomey, S.: Pollution and the Planetary Albedo, Atmos. Environ., 8, 1251-1256, doi:10.1016/0004-6981(74)90004-3, 1974.

Tzivion (Tzitzvashvili), S., Feingold, G., and Levin, Z.: An efficient numerical solution to the stochastic collection equation, J. Atmos. Sci., 44, 3139-3149, doi:10.1175/15200469(1987)044\%3C3139\%3AAENSTT\%3E2.0.CO\%3B2, 1987.

Vehkamäki, H., Kulmala, M., Napari, I., Lehtinen, K. E. J., Timmreck, C., Noppel, M., and Laaksonen, A.: An improved parameterization for sulfuric acid-water nucleation rates for tropospheric and stratospheric conditions, J. Geophys. Res., 107, 4622, doi:10.1029/2002JD002184, 2002.
Vuollekoski, H., Nieminen, T., Paasonen, P., Sihto, S.-L., Boy, M., Manninen, H., Lehtinen, K., Kerminen, V.-M., and Kulmala, M.: Atmospheric nucleation and initial steps of particle growth: Numerical comparison of different theories and hypotheses, Atmos. Res., 98, 229-236, doi:10.1016/j.atmosres.2010.04.007, 2010.

Wang, M. and Penner, J. E.: Aerosol indirect forcing in a global model with particle nucleation, Atmos. Chem. Phys., 9, 239-260, doi:10.5194/acp-9-239-2009, 2009.

Weber, R. J., McMurry, P. H., Eisele, F. L., and Tanner, D. J.: Measurement of Expected Nucleation Precursor Species and 3-500-nm Diameter Particles at Mauna Loa Observatory, Hawaii, J. Atmos. Sci., 52, 2242-2257, doi:10.1175/15200469(1995)052<2242:MOENPS>2.0.CO;2, 1995.

Weber, R. J., Marti, J. J., McMurry, P. H., Eisele, F. L., Tanner, D. J., and Jefferson, A.: Measurements of new particle formation and ultrafine particle growth rates at a clean continental site, J. Geophys. Res., 102, 4375, doi:10.1029/96JD03656, 1997.

Westervelt, D. M., Pierce, J. R., Riipinen, I., Trivitayanurak, W., Hamed, A., Kulmala, M., Laaksonen, A., Decesari, S., and Adams, P. J.: Formation and growth of nucleated particles into cloud condensation nuclei: model-measurement comparison, Atmos. Chem. Phys., 13, 7645-7663, doi:10.5194/acp-13-76452013, 2013.

Wu, Z., Hu, M., Yue, D., Wehner, B., and Wiedensohler, A.: Evolution of particle number size distribution in an urban atmosphere during episodes of heavy pollution and new particle formation, Sci. China Earth Sci., 54, 1772-1778, doi:10.1007/s11430-0114227-9, 2011.

Yu, F.: Ion-mediated nucleation in the atmosphere: Key controlling parameters, implications, and look-up table, J. Geophys. Res., 115, D03206, doi:10.1029/2009JD012630, 2010.

Yu, F. and Luo, G.: Simulation of particle size distribution with a global aerosol model: contribution of nucleation to aerosol and CCN number concentrations, Atmos. Chem. Phys., 9, 76917710, doi:10.5194/acp-9-7691-2009, 2009.

Yu, F. and Turco, R. P.: The size-dependent charge fraction of sub-3$\mathrm{nm}$ particles as a key diagnostic of competitive nucleation mechanisms under atmospheric conditions, Atmos. Chem. Phys., 11, 9451-9463, doi:10.5194/acp-11-9451-2011, 2011.

Zhang, R., Suh, I., Zhao, J., Zhang, D., Fortner, E. C., Tie, X., Molina, L. T., and Molina, M. J.: Atmospheric New Particle Formation Enhanced by Organic Acids, Science, 304, 1487-1490, doi:10.1126/science.1095139, 2004. 